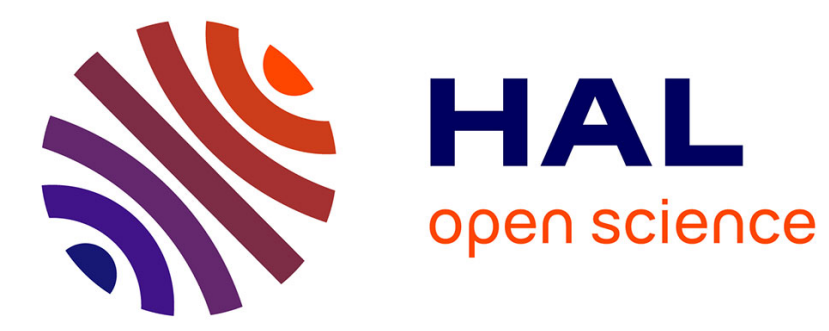

\title{
A ferromagnetic $\mathrm{Ni}$ ( ii ) $-\mathrm{Cr}$ ( iii ) single-chain magnet based on pentagonal bipyramidal building units
}

Kateryna Bretosh, Virginie Béreau, Carine Guyard-Duhayon, Céline Pichon, Jean-Pascal Sutter

\section{To cite this version:}

Kateryna Bretosh, Virginie Béreau, Carine Guyard-Duhayon, Céline Pichon, Jean-Pascal Sutter. A ferromagnetic $\mathrm{Ni}$ ( ii ) $-\mathrm{Cr}$ ( iii ) single-chain magnet based on pentagonal bipyramidal building units. Inorganic Chemistry Frontiers, 2020, 7 (7), pp.1503-1511. 10.1039/C9QI01489F . hal-02533614

\section{HAL Id: hal-02533614 \\ https://hal.science/hal-02533614}

Submitted on 10 Nov 2020

HAL is a multi-disciplinary open access archive for the deposit and dissemination of scientific research documents, whether they are published or not. The documents may come from teaching and research institutions in France or abroad, or from public or private research centers.
L'archive ouverte pluridisciplinaire HAL, est destinée au dépôt et à la diffusion de documents scientifiques de niveau recherche, publiés ou non, émanant des établissements d'enseignement et de recherche français ou étrangers, des laboratoires publics ou privés. 


\title{
Ferromagnetic Ni(II)-Cr(III) Single-chain magnet based on pentagonal bipyramid building units
}

\author{
Kateryna Bretosh, ${ }^{1}$ Virginie Béreau, ${ }^{1,2}$ Carine Duhayon, ${ }^{1}$ Céline Pichon, ${ }^{1}$ Jean-Pascal Sutter ${ }^{1 *}$ \\ ${ }^{1}$ Laboratoire de Chimie de Coordination du CNRS (LCC-CNRS), Université de Toulouse, CNRS, Toulouse, \\ France \\ ${ }^{2}$ Université de Toulouse, Institut Universitaire de Technologie Paul Sabatier-Département de Chimie, \\ Av. Georges Pompidou, , F-81104 Castres, France \\ * sutter@Icc-toulouse.fr
}

\begin{abstract}
:
A Ni(II) complex harnessed in pentagonal bipyramid environment by a rigid $\mathrm{N}_{5}$-macrocyclic ligand (i.e. 1,3,10,12-tetramethyl-1,2,11,12tetraaza[3](2,6)-pyridino[3](2,9)-1,10-phenanthrolinophane-2,10-diene) is shown to exhibit an axial anisotropy with a ZFS $D$ parameter in the order of -10 to $-15 \mathrm{~cm}^{-1}$, and this anisotropy is not significantly changed by apical ligand substitution. Using the latter complex as building unit, a ferromagnetic 1-D CN-bridged $\mathrm{Ni}-\mathrm{Cr}$ coordination polymer with SCM behavior characterized by a barrier of magnetization reversal $U_{\text {eff }} / k_{B}=54$

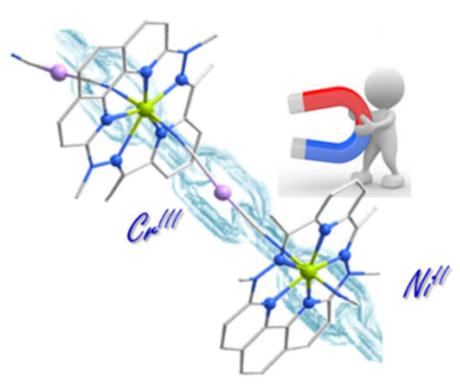
$\mathrm{K}\left(37 \mathrm{~cm}^{-1}\right)$ with $\tau_{0}=2.28 \times 10^{-11} \mathrm{~s}$ was achieved. $\operatorname{The} \mathrm{Cr}(\mathrm{III})$ complex involved in the design was chosen to favor parallel organization of the anisotropy axes of the $\mathrm{Ni}$ units along the 1-D array, and thus maximize the magnetic anisotropy of the supramolecular system. A related chain compound made with diamagnetic $\left[\mathrm{Ni}(\mathrm{CN})_{4}\right]^{2-}$ units, and a trinuclear $\mathrm{CN}$-bridged $\left[\mathrm{NiCr}_{2}\right]$ complex enabled assessing respectively, the magnetic anisotropy of $\mathrm{Ni}(\mathrm{II})$ in this coordination sphere, and its exchange interaction with $\mathrm{Cr}(\mathrm{III})$ found to be ferromagnetic and in the order of $10 \mathrm{~cm}^{-1}$. The crystal structures and magnetic behaviors of all compounds are reported.
\end{abstract}




\section{INTRODUCTION}

Remarkable research effort has been dedicated to the development of discrete molecular magnets, such as single-molecule and single-chain magnets (i.e. SMM \& SCM) aimed at behaving as bi-stable magnetic units. This process required to address more fundamental questions in relation with the magnetic properties and chemical constructions of such materials. One important challenge concerns the control of the magnetic anisotropy by design because the temperature at which the magnetization relaxation of a molecular magnet gets frozen is directly related to its anisotropy. ${ }^{1}$ This becomes particularly challenging for polynuclear nanomagnets. In this context, $3 \mathrm{~d}$ metal complexes with pentagonal bipyramid geometry are currently attracting interest. Such coordination polyhedra results in substantial magnetic anisotropy for $3 \mathrm{~d}$ metal ions with suitable electronic configurations. ${ }^{2,3}$ For instance, $\mathrm{Fe}(\mathrm{II})$ and $\mathrm{Ni}(\mathrm{II})$ exhibit easy-axis anisotropy with zero-field splitting parameter $D$ in the range of -10 to $-20 \mathrm{~cm}^{-1}$, whereas Co(II) has planar anisotropy with $D$ values around $30 \mathrm{~cm}^{-1}$. 4 . Moreover, the structural robustness of this coordination geometry makes such complexes suitable building units for polynuclear compounds. ${ }^{16}$ These characteristics provide a unique opportunity to design polynuclear nano-magnets taking advantage of the large magnetic anisotropy of the pentagonal bipyramid complexes, especially those with Ising-type anisotropy. Some examples have been reported, ${ }^{6,17-22}$ but they mainly involve Fe(II) as anisotropic unit whereas only one SMM with heptacoordinated $\mathrm{Ni}$ (II) was achieved. Forasmuch as the magnetic anisotropy is very similar for the two metal centers, related achievements could be expected. However, $\mathrm{Ni}(\mathrm{II})$ is prone to Jahn-Teller effect that leads to distortion of the coordination sphere and may result in drastic decrease of the magnetic anisotropy. ${ }^{23}$ With a flexible ligand this may even result in a structure reorganization in which the $\mathrm{Ni}$ is no longer heptacoordinated (see Figure S1).

Here, we show that a $\mathrm{Ni}(\mathrm{II})$ harnessed in pentagonal bipyramid environment by a rigid macrocyclic ligand can undergo apical ligand substitution with no significant alteration of its magnetic anisotropy. The macrocyclic phenanthroline based ligand $L^{\text {NSPhenMe }}$ (i.e. 1,3,10,12-tetramethyl-1,2,11,12tetraaza[3](2,6)-pyridino[3](2,9)-1,10-phenanthrolinophane-2,10-diene, Scheme 1) retained our attention because it is obviously stiff and symmetrical with five coordinating nitrogen atoms. A variety of $3 \mathrm{~d}$ metal complexes characterized by a pentagonal bipyramid coordination environment based on this ligand was reported since $1980 ;.{ }^{15,24-28}$ this included a Ni(II) derivative. ${ }^{29}$

Using the latter complex as building unit, we prepared a 1-D CN-bridged $\mathrm{Ni}-\mathrm{Cr}$ coordination polymer which is the first example of a ferromagnetic SCM with heptacoordinated $\mathrm{Ni}(\mathrm{II})$ as the source of Ising anisotropy. A related chain compound involving diamagnetic $\left[\mathrm{Ni}(\mathrm{CN})_{4}\right]^{2-}$ as connector, and a trinuclear $\mathrm{CN}$-bridged $\left[\mathrm{NiCr}_{2}\right]$ complex enabled assessing respectively, the magnetic anisotropy of $\mathrm{Ni}$ in this coordination sphere, and its exchange interaction with $\mathrm{Cr}(\mathrm{III})$. The crystal structures and magnetic behaviors of all compounds are reported. 


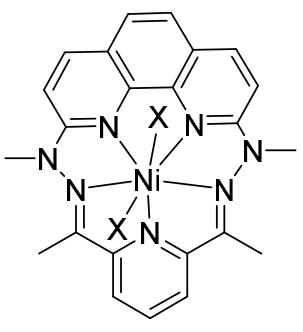

$\left[\mathrm{NiL}^{\mathrm{N} 5 \mathrm{PhenMe}} \mathrm{X}_{2}\right]$

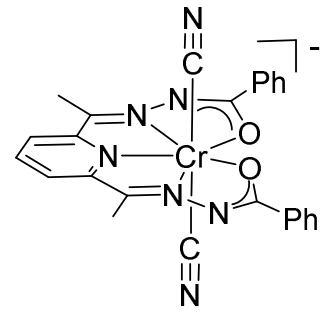

$\left[\mathrm{CrL}^{\mathrm{N} 3 \mathrm{O} 2 \mathrm{Ph}}(\mathrm{CN})_{2}\right]^{-}$

1: $\left[\mathrm{NiL}^{\mathrm{N} 5 \mathrm{PhenMe}}\left(\mathrm{H}_{2} \mathrm{O}\right)_{2}\right] \cdot 2 \mathrm{BF}_{4}$

2: 1-D [NiL $\left.{ }^{\mathrm{N} 5 \mathrm{PhenMe}}\left\{\mathrm{Ni}(\mathrm{CN})_{4}\right\}\right] \cdot 0.5 \mathrm{H}_{2} \mathrm{O}$

3: $\left[\mathrm{NiL}^{\mathrm{N} 5 \mathrm{PhenMe}}\left\{\mathrm{CrL}^{\mathrm{N} 3 \mathrm{O} 2 \mathrm{Ph}}(\mathrm{CN})_{2}\right\}_{2}\right] \cdot 2 \mathrm{H}_{2} \mathrm{O}$

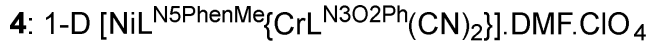

Scheme 1. Sketches of the heptacoordinated metal complexes involved as building units, and formula with label of the compounds investigated.

\section{RESULTS AND DISCUSSION}

\section{Synthesis and Crystal structures:}

$\left[\mathrm{NiL}^{\mathrm{N} S \mathrm{PhenMe}}\left(\mathrm{H}_{2} \mathrm{O}\right)_{2}\right] \cdot 2 \mathrm{BF}_{4}, \mathbf{1}$, was obtained according to the reported procedure ${ }^{29}$ and subsequently crystallized from $\mathrm{MeOH}$. Its reaction with stoichiometric amount of $\mathrm{K}_{2}\left[\mathrm{Ni}(\mathrm{CN})_{4}\right]$ afforded $\left[\left\{\mathrm{NiL}^{\mathrm{N} 5 \mathrm{PhenMe}}\right\}\left\{\mathrm{Ni}(\mathrm{CN})_{4}\right\}\right] \cdot 0.5 \mathrm{H}_{2} \mathrm{O}, 2$. The trinuclear complex $\left[\left\{\mathrm{NiL}^{\mathrm{N} 5 \mathrm{PhenM}} \mathrm{\}}\left\{\mathrm{CrL}^{\mathrm{N} 3 \mathrm{O} 2 \mathrm{Ph}}(\mathrm{CN})_{2}\right\}_{2}\right] \cdot 2 \mathrm{H}_{2} \mathrm{O}, \mathbf{3}\right.$, was formed by reaction of 1 with $\mathrm{K}\left[\mathrm{CrL}^{\mathrm{N} 302 \mathrm{Ph}}(\mathrm{CN})_{2}\right]^{30}$ in 1:2 ratio in $\mathrm{H}_{2} \mathrm{O}-\mathrm{EtOH}$. Same reagents but with 1:1 ratio in $\mathrm{DMF}$ and in the presence of an excess of $\mathrm{ClO}_{4}^{-}$anion yielded 1-D $\left[\left\{\mathrm{NiL}^{\mathrm{N} 5 \mathrm{PhenMe}}\right\}\left\{\mathrm{CrL}^{\mathrm{N} 302 \mathrm{Ph}}(\mathrm{CN})_{2}\right\}\right] . \mathrm{DMF} \cdot \mathrm{ClO}_{4}$, 4. All compounds were obtained in crystalline form as pure phases and subsequent investigations were performed on freshly prepared samples.

Crystal structures for 1-4 have been established from single-crystal diffraction data collected at 100 $\mathrm{K}$; crystallographic data can be found in Table S1 (Supporting Information). The crystals of $\left[\mathrm{NiL}^{\mathrm{NSPhenMe}}\left(\mathrm{H}_{2} \mathrm{O}\right)_{2}\right] \cdot 2 \mathrm{BF}_{4}, \mathbf{1}$, obtained in $\mathrm{MeOH}$ have cell parameters different to the known structure; ${ }^{29}$ however the molecular structures are very similar. Complex 1 (Figure 1 and S2) corresponds to the anticipated heptacoordinated complex with the $\mathrm{Ni}$ ion sitting in a pentagonal bipyramid polyhedron. The coordination sphere comprises five $\mathrm{N}$-atoms of the $\mathrm{L}^{\mathrm{N} 5 \mathrm{Ph} n \mathrm{nMe}}$ ligand located in the equatorial positions, and two $\mathrm{H}_{2} \mathrm{O}$ molecules coordinated by their $\mathrm{O}$-atom in the apical positions. The charge of the metal complex is compensated by two $\mathrm{BF}_{4}^{-}$anions. A stereochemical analysis performed with $\mathrm{SHAPE}^{31}$ confirmed a polyhedral shape close to the pentagonal bipyramid geometry ${ }^{32}$ for the coordination sphere for $\mathrm{Ni}(\mathrm{II})$ (Table S2). However, examination of the Ni-N bond lengths indicates sensible differences with distances spanning from 2.03 to $2.43 \AA$ (see figure caption). This indicates that the $\mathrm{Ni}$ ion is not centered in the macrocyclic ligand cavity, a feature also found in 2-4. The apical Ni-O bonds are very similar with a mean distance of $2.089 \AA$. The alignment of the axial atoms and $\mathrm{Ni}$ is almost perfect with bond angles of $177.69^{\circ}$

A view of the crystal structure for 1-D $\left[\left\{\mathrm{NiL}^{\mathrm{NSPhenMe}}\right\}\left\{\mathrm{Ni}(\mathrm{CN})_{4}\right\}\right] \cdot 0.5 \mathrm{H}_{2} \mathrm{O}, 2$, is shown in Figure 1. It consists in a 1-D coordination polymer made up by an alternation of $\left[\mathrm{NiL}^{\mathrm{N5PhenMe}}\right]^{2+}$ and $\left[\mathrm{Ni}(\mathrm{CN})_{4}\right]^{2-}$ units interlinked by $\mathrm{CN}$-bridges. The coordination environment of the heptacoordinated center is similar to that found in $\mathbf{1}$ except for apical positions that are now occupied by $\mathrm{N}$-atoms from 
cyanides. Consequently, each [NiL $\left.{ }^{\mathrm{NSPhenMe}}\right]$ moiety is linked to two $\left[\mathrm{Ni}(\mathrm{CN})_{4}\right]$ moieties. Likewise, each of the cyanometallate is coordinated to two [ $\mathrm{NiL}^{\mathrm{NSPhenMe}}$ ] moieties by two of its $\mathrm{CN}^{-}$ligands in trans positions. Like for 1, the equatorial Ni2-N bond distances span from 2.484 to $3.062 \AA$ (see caption of Figure 1), while apical bonds are shorter. The Ni-N-C connections are very slightly bent with a mean angle of $167.6^{\circ}$ resulting in a fairly straight linear chain arrangement (see Figure S3). The intramolecular distance between two paramagnetic Ni centers (i.e. Ni2) is 10.030(1) $\AA$, and the shortest Ni2-Ni2 separation between neighboring chains is 8.2785(9) $\AA$.

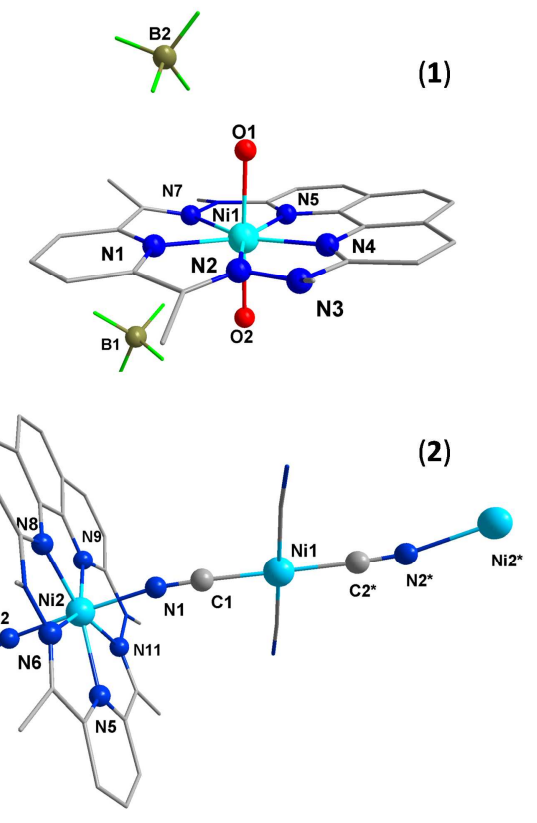

Figure 1. Molecular structures for $\left[\mathrm{NiL}^{\mathrm{N} 5 \mathrm{PhenMe}}\left(\mathrm{H}_{2} \mathrm{O}\right)_{2}\right] \cdot 2 \mathrm{BF}_{4}, \quad \mathbf{1}$, and $\left[\left\{\mathrm{NiL}^{\mathrm{N} 5 \mathrm{PhenMe}}\right\}\left\{\mathrm{Ni}(\mathrm{CN})_{4}\right\}\right]_{n} \cdot 0.5 \mathrm{H}_{2} \mathrm{O}, 2$ (the $\mathrm{L}^{\mathrm{N} 5 \text { PhenMe }}$ was found disordered over two positions, only one is depicted; complete position diagram is given in Fig. S3). $\mathrm{H}$ atoms are not shown. Selected bond distances $(\AA)$ and angles $\left({ }^{\circ}\right)$ : for 1, Ni-N1, 2.132(2); Ni-N2, 2.213(2); Ni-N4, 2.030(2); Ni-N5, 2.123(2); Ni-N7, 2.434(2); Ni-O1, 2.098(2) ; Ni-O2, 2.080(2) ; for 2, Ni2-N1, 2.046(5) ; Ni2-N2, 2.064(7) ; Ni2-N5, 2.17(1); Ni2-N6, 2.393(6) ; Ni2-N8, 2.099(5) ; Ni2-N9, 2.061(6) ; Ni2-N11, 2.262(6); Ni2-N1-C1, 167.4(4); Ni2-N2-C2, 167.9(4), N1-Ni2-N2, 177.7(1). *symmetry operation, $0.5+x, 0.5-y,-0.5+z$.

The crystal structure of $\left[\left\{\mathrm{NiL}^{\mathrm{N5PhenMe}}\right\}\left\{\mathrm{CrL}^{\mathrm{N} 302 \mathrm{Ph}}(\mathrm{CN})_{2}\right\}_{2}\right] .2 \mathrm{H}_{2} \mathrm{O}, 3$, consists in a neutral trinuclear complex crystallized with two $\mathrm{H}_{2} \mathrm{O}$ molecules (Figure 2). $\mathrm{Two} \mathrm{Cr}(\mathrm{III})$ units are linked by one of their $\mathrm{CN}^{-}$groups to the apical positions of a central metal Ni(II). All metal centers exhibit a slightly distorted pentagonal bipyramid coordination sphere. For the $\mathrm{Ni}$ ion the equatorial coordination positions are occupied by five $\mathrm{N}$ and for the $\mathrm{Cr}$ (III) centers by $3 \mathrm{~N}$ and $2 \mathrm{O}$ atoms from the pentadentate ligands; all the metal centers have axial positions occupied by $\mathrm{CN}$ groups. These are bonded to $\mathrm{Cr}(\mathrm{III})$ by their $\mathrm{C}$ atoms whereas the coordination to $\mathrm{Ni}$ takes place by their $\mathrm{N}$-terminals. The $\mathrm{Ni}-\mathrm{N}-\mathrm{C}$ linkages are slightly bent with an angle of $165.5(4)^{\circ}$, whereas the $\mathrm{Cr}-\mathrm{C}-\mathrm{N}$ linkages are more linear with a mean angle of $174.0^{\circ}$. The $L^{\text {NSPhenMe }}$ ligand was found disordered and solved as two superimposed inversed orientations (Figure S4); this results in less accurate bond distances. Nevertheless, a bond length 
distribution similar to that found in $\mathbf{1}$ and $\mathbf{2}$ can be evidenced (see figure 1 caption). The shortest intermolecular distance between two metal centers is found between two $\mathrm{Cr}$ ions with 8.2840(9) $\AA$. The polyhedral shape, evaluated by SHAPE, indicates a slightly distorted pentagonal bipyramid coordination environment for Ni similar to that found in $\mathbf{1}$ and $\mathbf{2}$ (Table S2).

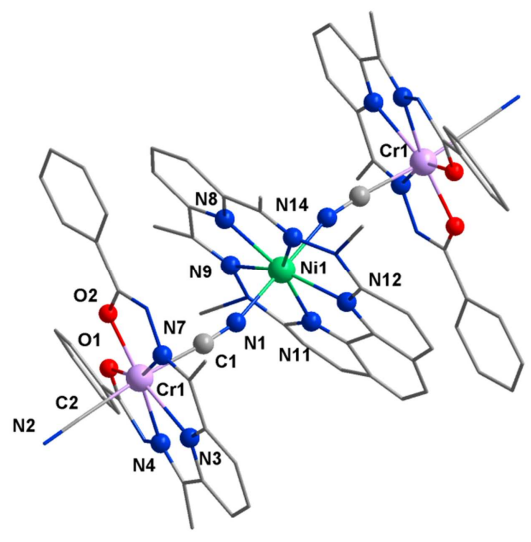

Figure 2. $\left[\left\{\mathrm{NiL}^{\mathrm{N} 5 \mathrm{PhenMe}}\right\}\left\{\mathrm{CrL}^{\mathrm{N} 3 \mathrm{O} 2 \mathrm{Ph}}(\mathrm{CN})_{2}\right\}_{2}\right] \cdot 2 \mathrm{H}_{2} \mathrm{O}, 3$ (the $\mathrm{L}^{\mathrm{N} 5 \mathrm{Ph} e n M e}$ was found disordered over two positions, only one is depicted; complete position diagram is given in Figure S4; $\mathrm{H}$ atoms and solvates molecules are not shown). Selected bond distances $(\AA)$ ) and angles ( $\left.{ }^{\circ}\right)$ :Ni1-N1, 2.075(4); Ni1-N8, 2,116(6); Ni1-N9, 2.119(1); Ni1-N11, 2.167(8); Ni1-N12, 2.166(8); Ni1-N14, 2.406(8); Cr1-O1, 1.943(3); Cr1-O2, 1.962(3); Cr1-N3, 2.395(3); Cr1-N4, 2.199(3); Cr1-N7, 2.229(3); Cr1-C1, 2.063(3); Cr1-C2, 2.083(4); Ni1-N1-C1, 165.5(4); Cr1-C1-N1, 172.9(3); Cr1-C2-N2, 175.2(4).

The structure for $\left[\left\{\mathrm{NiL}^{\mathrm{N5PhenMe}}\right\}\left\{\mathrm{CrL}^{\mathrm{N} 302 \mathrm{Ph}}(\mathrm{CN})_{2}\right\}\right]$. DMF. $\mathrm{ClO}_{4}, 4$, consists in an 1-D coordination polymer made of an alternation of $\left[\mathrm{Cr}\left(\mathrm{L}^{\mathrm{N} 302 \mathrm{Ph}}\right)(\mathrm{CN})_{2}\right]^{-}$and $\left[\mathrm{NiL}^{\mathrm{N} 5 \mathrm{PhenMe}}\right]^{2+}$ moieties which charge is neutralized by a $\mathrm{ClO}_{4}{ }^{-}$anion. The chain crystalizes with 1 molecule of DMF per [NiCr] unit. Each $\mathrm{Cr}$ is linked to two $\mathrm{Ni}$ centers by its $\mathrm{CN}^{-}$ligands that coordinate in the apical positions of the metal complex. Likewise, each $\mathrm{Ni}$ is linked to two $\mathrm{Cr}$ units, thus developing a 1-D coordination polymer. The $\mathrm{Ni}^{2+}$ and $\mathrm{Cr}^{3+}$ complexes exhibit slightly distorted pentagonal bipyramidal geometry. The $\mathrm{CN}$ linkages are close to linear with angles of $167.5(3)^{\circ}$ and $170.7(3)^{\circ}$ for $\mathrm{Ni}-\mathrm{N}-\mathrm{C}$, and $171.6(3)^{\circ}$ and $172.3(3)^{\circ}$ for $\mathrm{Cr}-\mathrm{C}-\mathrm{N}$. In the crystal packing the chains run in parallel along the $[0,0,1]$ direction (Figure S6). The shortest inter-chain distance between two paramagnetic ions is found between a $\mathrm{Ni}$ and a $\mathrm{Cr}$ center with 11.66(8) $\AA$; the shortest $\mathrm{Ni} \cdots \mathrm{Ni}$, and $\mathrm{Cr} \cdots \mathrm{Cr}$ are respectively, 13.46(8), and 12.06(9) $\AA$. The $\mathrm{Cr}$ complex involved in the design of $\mathbf{4}$ was chosen to favor parallel organization of the [NiL ${ }^{\mathrm{N} 5 \mathrm{Ph} n \mathrm{nMe}}$ ] units along the 1-D array, and thus maximize the magnetic anisotropy of the supramolecular system. ${ }^{22,33,34}$ This is indeed obtained in $\mathbf{4}$ where the equatorial plans of two consecutive Ni units are tilted by an angle of just $4.13(9)^{\circ}$ (Figure S6). 


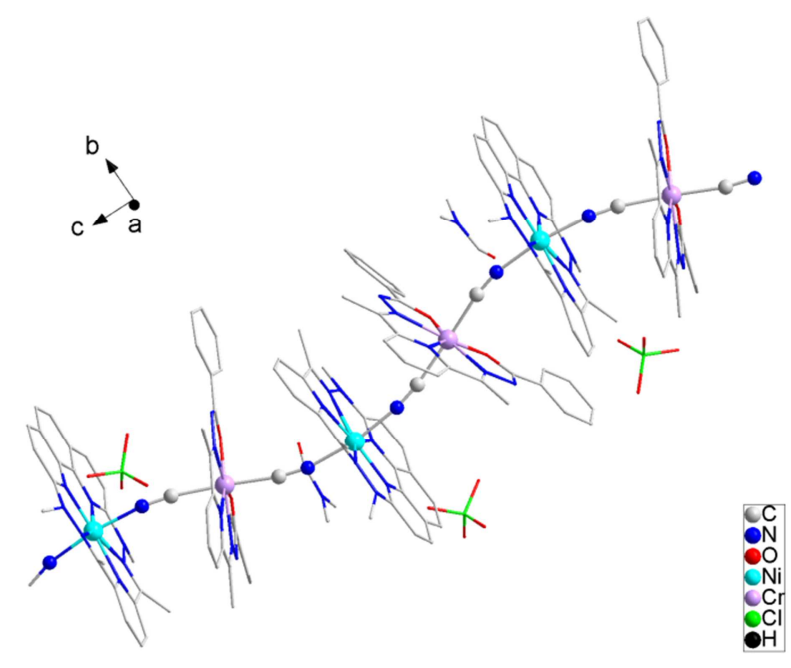

Figure 3. $\left[\left\{\mathrm{NiL}^{\mathrm{N} 5 \mathrm{PhenMe}}\right\}\left\{\mathrm{CrL}^{\mathrm{N} 3 \mathrm{O} 2 \mathrm{Ph}}(\mathrm{CN})_{2}\right\}\right]$. DMF. $\mathrm{ClO}_{4}$, 4: Molecular structure of the 1-D coordination polymer. A selection of bond distances and angles can be found in Figure S6.

The phase purity of the macroscopic samples for $\mathbf{3}$ and $\mathbf{4}$ was confirmed by X-ray powder diffraction (Figure S5 and S7).

\section{Magnetic properties:}

Magnetic measurements for all compounds have been performed on microcrystalline powder mixed to grease. The temperature dependence of the magnetic susceptibility was collected between 300 and $2 \mathrm{~K}$ with an applied static field of $0.1 \mathrm{~T}(1 \mathrm{kOe})$. The field dependence of the magnetization was measured for fields up to $5 \mathrm{~T}$.

Compounds 1 and $\mathbf{2}$ have been investigated to assess their magnetic anisotropy, their magnetic behaviors are plotted in Figure 4 for $\mathbf{2}$ and S8 for $\mathbf{1}$. For each, the temperature dependence of $\chi_{M} T$ is mainly characteristic for a paramagnetic behavior. The values for $\chi_{M} T$ obtained at $300 \mathrm{~K}$ are respectively, 1.12 , and $1.17 \mathrm{~cm}^{3} \mathrm{~mol}^{-1} \mathrm{~K}$. They are in agreement with the expected contribution for a spin $S=1$ with $g$ factor slightly larger than 2 . Upon cooling, $\chi_{M} T$ remained constant to around $20 \mathrm{~K}(1)$, and $22 \mathrm{~K}(2)$ before dropping to respectively 0.53 , and $0.59 \mathrm{~cm}^{3} \mathrm{~mol}^{-1} \mathrm{~K}$ for $2 \mathrm{~K}$. Field-dependent magnetization measurements showed that the $M=f(H)$ isotherms at $2 \mathrm{~K}$ did not reach saturation even at $50 \mathrm{kOe}$ and the maximum magnetization values of 1.43 , and $1.45 \mu_{\mathrm{B}}$ are significantly lower than the expected values for $M_{S}=g \times S,(S=1$ and $g=2.13$, and 2.12 considering the values indicated above). Moreover, the behaviors obtained for different temperatures between 2 and $8 \mathrm{~K}$ do not superpose when plotted as $M=f(H / T)$ (Figure 4 for 2 and $S 8$ for 1). Such a behavior suggests the presence of significant magnetic anisotropy. The zero-field splitting (ZFS) parameters of the $\mathrm{Ni}(I I)$ centers were assessed by fitting simultaneously the $\chi_{M} T=f(T)$ and $M=f(H)$ behaviors for different temperatures using the PHI software. ${ }^{35}$ In all cases, a very good agreement between calculated and experimental behaviors has been obtained (see Figures 4 and S8) yielding for $1 D=-10.95 \pm 0.04 \mathrm{~cm}^{-}$ ${ }^{1}, E=1.515 \pm 0.008 \mathrm{~cm}^{-1}, g=2.11$, and for $2, D=-14.4 \pm 0.1 \mathrm{~cm}^{-1}, E=1.86 \pm 0.02 \mathrm{~cm}^{-1}, g=2.13$. The obtained negative $D$ parameter is in agreement with the easy-axis anisotropy expected for $\mathrm{Ni}(\mathrm{II})$ in 
pentagonal bipyramid coordination sphere and compares well with values mentioned in literature for heptacoordinated Ni complexes (from -15 to $-6 \mathrm{~cm}^{-1}$ ). ${ }^{5,8,9,19,36}$ The rather similar $D$ values for $\mathbf{1}$ and $\mathbf{2}$ suggests that the nature of the apical ligands has a small effect on the anisotropy exhibited by the Ni; however, it is interesting to note that largest anisotropy is found with cyano-metallates in the apical positions. Despite their significant uniaxial magnetic anisotropy, no slow relaxing magnetization could be evidenced for these complexes.

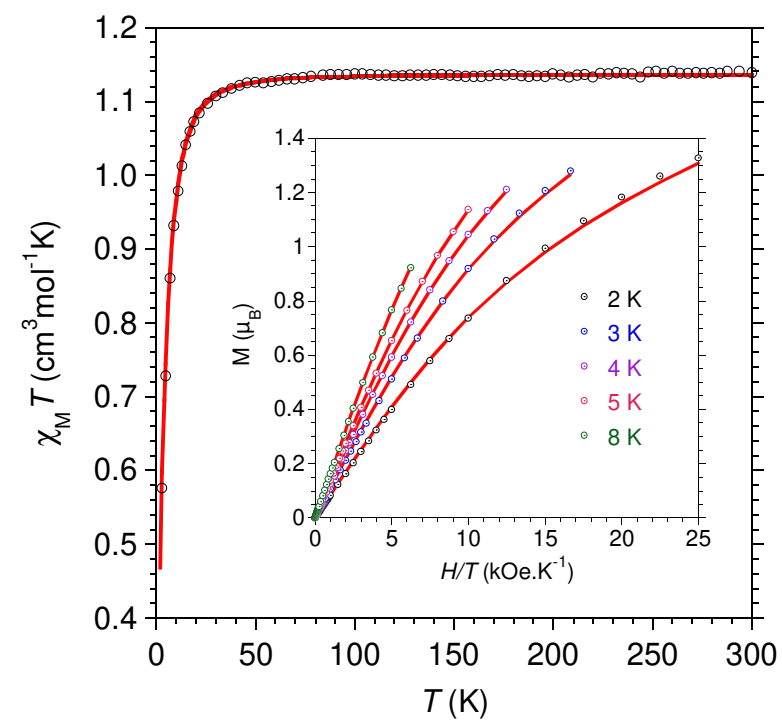

Figure 4. Experimental $(O)$ and calculated $(-) \chi_{M} T=f(T)$, and (insert) $M=f(H / T)$ for 2.

For trinuclear complex 3 (Figure 5), the value of $5.12 \mathrm{~cm}^{3} \mathrm{~mol}^{-1} \mathrm{~K}$ observed for $\chi_{\mathrm{M}} T$ at $300 \mathrm{~K}$ is in a good agreement with the Curie contribution of two $S=3 / 2$ and one $S=1\left(4.85\right.$ for $\left.g_{\mathrm{Ni}}=2.1\right)$. This value gradually increases as the temperature is lowered to reach $8.36 \mathrm{~cm}^{3} \mathrm{~mol}^{-1} \mathrm{~K}$ at $9 \mathrm{~K}$ before decreasing for lower temperatures. Such a behavior is indicative of ferromagnetic $\mathrm{Cr}-\mathrm{Ni}$ interactions, and the decrease observed for lower temperatures can be explained by ZFS and possibly intermolecular interactions. The field dependence of magnetization was measured between 2 and $8 \mathrm{~K}$ (Figure 5 , insert). The largest magnetization for $50 \mathrm{kOe}$ was reached at $2 \mathrm{~K}$ with $6.54 \mu_{B}$, that is less than expected for a ground spin state of $\mathrm{S}=4$ which suggests substantial magnetic anisotropy. AC susceptibility data were recorded in zero field and with applied field but not out of phase component, $\chi_{M}{ }^{\prime \prime}$, was found, which indicated absence of slow relaxation of the magnetization for 3.

The strength of the exchange interaction between $\mathrm{Ni}$ and the two $\mathrm{Cr}$ centers $\left(\mathrm{J}_{\mathrm{Nir}}\right)$ was estimated by fitting the $\chi_{M} T=f(T)$ behavior (model Hamiltonian $H=-J\left(\boldsymbol{S}_{N i} \cdot \boldsymbol{S}_{C r 1}+\boldsymbol{S}_{N i} \cdot \boldsymbol{S}_{C r 2}\right)$ ). The ZFS splitting contribution for $\mathrm{Ni}$ was included and fixed to the value obtained for 2 , namely $D_{\mathrm{Ni}}=-14 \mathrm{~cm}^{-1}$; and possible intermolecular interactions have been considered within the mean-field approximation (zj'). The best fit to experimental data was obtained for $J_{\mathrm{NiCr}}=10.76 \pm 0.05 \mathrm{~cm}^{-1}, \mathrm{~g}_{\mathrm{Ni}}=2.082 \pm 0.003, \mathrm{zj} \mathrm{j}^{\prime}=$ $0.064 \pm 0.001 \mathrm{~cm}^{-1}, D_{\mathrm{Ni}}=-14 \mathrm{~cm}^{-1}$ (fixed) confirming that ferromagnetic $\mathrm{Ni}-\mathrm{Cr}$ interactions take place in this compound and the small zj' value suggests weak intermolecular interactions. A very similar set of parameters was obtained by simultaneous analysis of $\chi_{\mathrm{M}} T=f(T)$ and $\mathrm{M}=f(H)$ with adjustable $D_{\mathrm{Ni}}$ but the value for the latter was not realistic (i.e. $-40 \mathrm{~cm}^{-1}$ ) and suppression of $z j^{\prime}$ did not change the outcome. 
The observed ferromagnetic $\mathrm{Ni}(\mathrm{II})-\mathrm{Cr}$ (III) interaction was anticipated from the spin distribution in $\left[\mathrm{Cr}\left(\mathrm{L}^{\mathrm{N} 302 \mathrm{Ph}}\right)(\mathrm{CN})_{2}\right]^{-}$showing that spin from $\mathrm{Cr}$ is delocalized on the $\pi$-orbitals of the $\mathrm{CN}$ ligands, ${ }^{30}$ and the magnetic d-orbital for $\mathrm{Ni}(\mathrm{II})$ in pentagonal bipyramid surrounding. ${ }^{4}$ Compound $\mathbf{3}$ provides the first experimental evidence and suggests that the strength of the $\mathrm{Ni}-\mathrm{Cr}$ exchange interaction is slightly weaker than the one usually found for related hexacoordinated centers. ${ }^{37,38}$

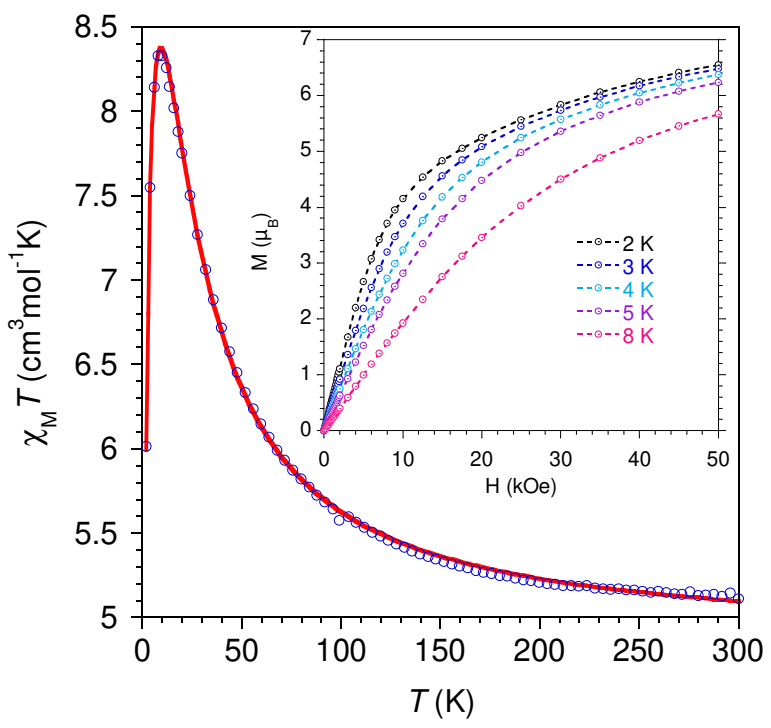

Figure 5. Experimental $(O)$ and calculated $(-)$ variation for $\chi_{M} T=f(T)$, and (insert) field dependence of the magnetization.

For the chain compound 4 , the $\chi_{\mathrm{M}} T$ value of $3.34 \mathrm{~cm}^{3} \mathrm{~K} \mathrm{~mol}^{-1}$ found at $300 \mathrm{~K}$ is slightly higher than expected for isolated $\mathrm{Cr}(\mathrm{III})$ and $\mathrm{Ni}(\mathrm{II})$ in a pentagonal-bipyramidal environment $\left(\mathrm{g}_{\mathrm{Cr}}=2, \mathrm{~g}_{\mathrm{Ni}}=2,1 \chi_{\mathrm{M}} T=\right.$ $1.87+1.1=2.97 \mathrm{~cm}^{3} \mathrm{~K} \mathrm{~mol}^{-1}$ ). It can be attributed to the ferromagnetic interaction between $\mathrm{Cr}$ (III) and $\mathrm{Ni}(\mathrm{II})$ centers. The value growths slightly as $T$ is lowered and below $50 \mathrm{~K}$ it sharply increases to reach $38 \mathrm{~cm}^{3} \mathrm{~K} \mathrm{~mol}^{-1}$ at $6 \mathrm{~K}$ follows by a quick decrease to $17 \mathrm{~cm}^{3} \mathrm{~K} \mathrm{~mol}^{-1}$ at $2 \mathrm{~K}$ (Figure 6). This magnetic comportment corresponds to a ferromagnetic chain behavior. The decrease below $6 \mathrm{~K}$ is attributed to saturation effect under applied field (i.e. $1 \mathrm{kOe}$ ) rather than to antiferromagnetic interchain interactions. This is supported by the behavior observed when a low field ( $50 \mathrm{Oe}$ ) was used (Figure S9). In this case, $\chi_{M}$ increased to larger values at low temperatures thus confirming the absence of sizeable antiferromagnetic interactions between the chains. The $\chi_{M} T$ behavior has been modeled between 300 and $5 \mathrm{~K}$ using an expression of the susceptibility for Heisenberg linear chains with alternating spins. ${ }^{39,} 40$ The ZFS of the $\mathrm{Ni}(\mathrm{II})$ center was not taken into account because it is expected to contribute mainly to the behavior below $5 \mathrm{~K}$. Best fit yielded $J=8.58 \pm 0.2 \mathrm{~cm}^{-1}, \mathrm{~g}_{\mathrm{Ni}}=2.09$ \pm 0.05 , and $\mathrm{g}_{\mathrm{cr}}=2.0$ (fixed) (Figure 6). The ferromagnetic exchange parameter compares well with that obtained for the Ni-Cr interaction in $\mathbf{3}\left(10.76 \mathrm{~cm}^{-1}\right)$. 

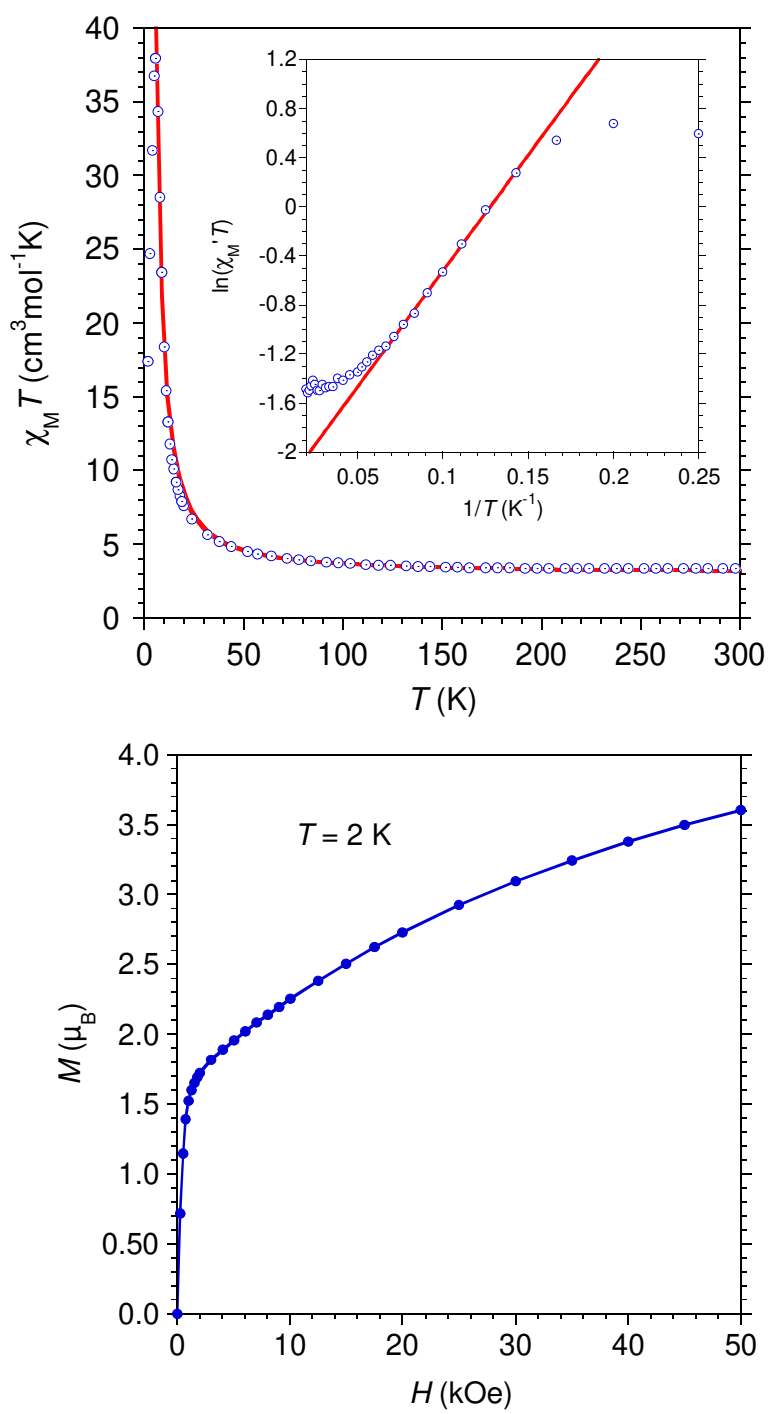

Figure 6. Magnetic behavior of chain 4: (top) Experimental $(O)$ and calculated, $(-) \chi_{M} T=f(T)$ behavior, the best fit (5-300 K) parameters are discussed in the text; (insert) $\ln \left(\chi_{M}^{\prime} T\right)=f(1 / T)$ with linear fit for the $T$ range 7-17 K; (bottom) field dependence of the magnetization at $2 \mathrm{~K}$.

The isothermal field dependence of the magnetization recorded at $2 \mathrm{~K}$ (Figure 6) shows a very fast increase for low field (to ca. $1 \mathrm{kOe}$ ) followed by smoother but steady increase without reaching saturation at $50 \mathrm{kOe}$. The lower than expected magnetization reached for high field (3.6 $\mu_{\mathrm{B}}$ for 50 kOe) compared to the $5 \mu_{\mathrm{B}}$ expected at saturation for an $S=5 / 2$ unit can be attributed to the anisotropy of the Ni center. The opening of a hysteresis loop was not observed at $2 \mathrm{~K}$.

The magnetic behavior for anisotropic 1-D systems has been described by Glauber ${ }^{41-43}$ and is given by $\chi_{\mathrm{M}} T=\mathrm{C}_{\text {eff }} \exp \left(\Delta_{\xi} / k_{\mathrm{B}} T\right)$, where $\mathrm{C}_{\text {eff }}$ is the effective Curie constant, $\Delta_{\xi}$ is the correlation energy, and $k_{\mathrm{B}}$ is the Boltzmann constant. Such a behavior is characterized by exponential dependence of $\chi_{M} T$ with decreasing $T$ in the absence of a dc field. For chain 4 , the $\ln \left(\chi_{M}^{\prime} T\right)$ vs $1 / T$ plot (Figure 6) where $\chi_{M}^{\prime}$ is the in-phase magnetic susceptibility measured in the absence of a dc field with an oscillating AC field of $3 \mathrm{Oe}(\mathrm{v}=100 \mathrm{~Hz})$, indeed shows a linear variation between 7 and $17 \mathrm{~K}$ that leads to a correlation energy of $\Delta_{\xi} / k_{\mathrm{B}}=19 \mathrm{~K}$. The lower temperature for the linear variation of $\ln \left(\chi_{\mathrm{M}}{ }^{\prime} T\right)$ allows to estimate 
the minimum number of [NiCr] units in a chain $\left(\mathrm{n} \approx 2 \xi \approx \exp \left(\Delta_{\xi} / k_{\mathrm{B}} T\right)\right.$ to be 15 ; which corresponds to a mean length of ca $13 \mathrm{~nm}$ for the coordination polymer. This rather limited number of correlated units points to a behavior governed by finite-size chains. In such a situation, and in the Ising limit $(D / J>$ $4 / 3)$, the $\mathrm{Cr}-\mathrm{Ni}$ exchange interaction can be deduced from the expression $\Delta_{\xi}=2|J| S_{\mathrm{Ni}} \times \mathrm{S}_{\mathrm{Cr}}$ giving $J=$ $6.3 \mathrm{~K}\left(4.4 \mathrm{~cm}^{-1}\right)$, a value slightly smaller but consistent with the value deduced from the $\chi_{\mathrm{M}} T$ vs $T$ behavior. The deviation from a linear increase for $\ln \left(\chi_{M}^{\prime} T\right)$ and the down-turn at low $T$ reveals existence of small antiferromagnetic interaction between chains.

AC susceptibility for chain 4 revealed frequency and temperature dependent in-phase $\left(\chi_{M}^{\prime}\right)$ and outof-phase $\left(\chi_{M}^{\prime \prime}\right)$ components of magnetic susceptibility in zero field below $6 \mathrm{~K}$ (Figures 7 and S9). Analysis of the Cole-Cole plots $\left(\chi_{M}{ }^{\prime \prime}\right.$ vs $\left.\chi_{M}{ }^{\prime}\right)$ indicate a rather narrow distribution width $(\alpha)$ of the relaxation time with values comprised between 0.12 and 0.21 (see Fig S9.3). The relaxation times ( $\tau$ ) were deduced from $\chi_{M}^{\prime \prime}=f(v)$ behaviors using a generalized Debye model and their temperature dependence was analyzed with the Arrhenius law $\left(\tau=\tau_{0} \exp \left(U_{\text {eff }} / k_{B} T\right)\right.$ ) (Figure 7). Chain 4 is characterized by a barrier of magnetization reversal $U_{\text {eff }} / k_{B}=54 \mathrm{~K}\left(37 \mathrm{~cm}^{-1}\right)$ with $\tau_{0}=2.28 \times 10^{-11} \mathrm{~s}$. In finite-size regime and according to the equation $U_{\text {eff }} / k_{\mathrm{B}}=\Delta_{\mathrm{ZFS}}+\Delta_{\xi}$ where $\Delta_{\mathrm{ZFs}}$ stands for the anisotropy contribution to the total energy barrier of the elementary magnetic units, a $\Delta_{\mathrm{ZFS}}=35 \mathrm{~K}$ is found. This allows estimating the anisotropy of a repeating [CrNi] unit given by $\Delta_{\mathrm{ZFS}}=\left|D_{\mathrm{CrNi}}\right| \cdot \mathrm{S}_{\mathrm{CrNi}}{ }^{2}$ to $\left|D_{\text {Nicr }}\right|=5.6 \mathrm{~K}\left(3.9 \mathrm{~cm}^{-1}\right)$.

The magnetic properties found for $\mathbf{4}$ are consistent with SCM behavior and illustrate the potential of pentagonal bipyramid $\mathrm{Ni}(I I)$ complexes to act as Ising-type building units. The energy barrier for the magnetization reversal, $\mathrm{U}_{\text {eff }} / k_{B}=54 \mathrm{~K}$, is remarkable considering the modest anisotropy of the $\mathrm{Ni}-\mathrm{Cr}$ units $\left(3.9 \mathrm{~cm}^{-1}\right)$ and moderate $\mathrm{Ni}-\mathrm{Cr}$ exchange interaction. This can be attributed to the careful design aimed at parallel alignment of their easy axes oriented along with the apical coordination sites. This situation contributes to maximize the chain anisotropy and contributes therefore to the energy barrier of magnetization reversal. 

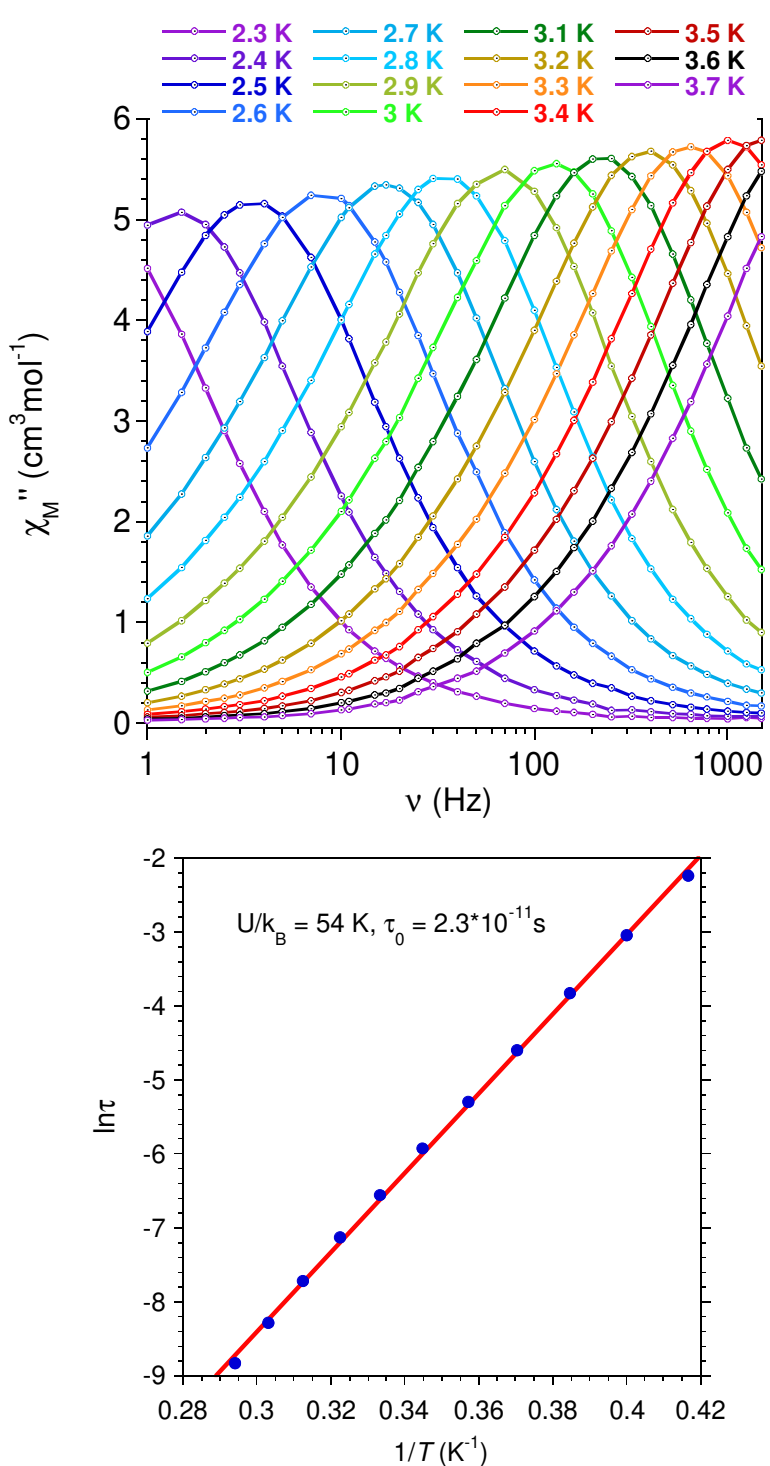

Figure 7. AC susceptibility behavior for $1 \mathrm{D}-\left[\left\{\mathrm{NiL}^{\mathrm{NSPhenMe}}\right\}\left\{\mathrm{CrL}^{\mathrm{N}}{ }^{\mathrm{NO} 2 \mathrm{Ph}}(\mathrm{CN})_{2}\right\}\right]$.DMF.ClO ${ }_{4}, 4$ : Frequency dependence of $\chi_{M}^{\prime \prime}$ for different temperatures and variation of $\ln \tau$ as a function of $1 / T$ with best fit.

\section{CONCLUDING REMARKS}

The results gathered show that $\mathrm{Ni}(\mathrm{II})$ harnessed by the rigid macrocyclic ligand $\mathrm{L}^{\mathrm{NSPhenMe}}$ exhibits an axial anisotropy characterized by a ZFS $D$ parameter in the order of -10 to $-15 \mathrm{~cm}^{-1}$, and this anisotropy is not significantly changed by apical ligand substitution unlike for homologous $\mathrm{Fe}$ (II) complexes. ${ }^{36}$ This suggests that the Jahn-Teller distortion that applies for $\mathrm{Ni}(\mathrm{II})$ is limited by the pentadente $\mathrm{L}^{\mathrm{N} \text { PhenMe }}$ ligand.

The magnetic behavior evidenced for $\mathbf{4}$ confirms that this Ni complex is a suitable building unit with well-controlled magnetic anisotropy for the design of polynuclear systems. In the present example, it was associated to a $\mathrm{Cr}(\mathrm{III})$-cyanometallate to achieve a ferromagnetic SCM. 


\section{EXPERIMENTAL}

Materials and synthesis. All reagents were obtained from commercially available sources and used as received unless otherwise noted. 2,9-dimethylhydrazin-1,10-phenanthroline was synthesized by adapting reported procedures. ${ }^{44,}{ }^{45}$ Crude $\left[\mathrm{NiL}^{\mathrm{NSPhenMe}}\left(\mathrm{H}_{2} \mathrm{O}\right)_{2}\right]\left[\mathrm{BF}_{4}\right]_{2}$ was obtained according to a literature procedure ${ }^{29}$ and crystallized as described below. $\mathrm{K}\left[\mathrm{CrL}^{\mathrm{N3O2Ph}}(\mathrm{CN})_{2}\right]$ was prepared following the reported procedure. ${ }^{30}$ Elemental $\mathrm{C}, \mathrm{H}$, and $\mathrm{N}$ analyses were performed on a Perkin-Elmer $2400 \mathrm{II}$ analyzer on freshly prepared and isolated samples. IR spectra were recorded in the $4000-600 \mathrm{~cm}^{-1}$ region with a Perkin-Elmer Spectrum 100 FTIR using the ATR mode.

$\left[\mathrm{NiL}^{\mathrm{NSPhenMe}}\left(\mathrm{H}_{2} \mathrm{O}\right)_{2}\right]\left[\mathrm{BF}_{4}\right]_{2}(\mathbf{1}) . \mathrm{NiCl}_{2} \cdot 4 \mathrm{H}_{2} \mathrm{O}(120 \mathrm{mg}, 0.5 \mathrm{mmol})$ was added to water $(70 \mathrm{~mL})$ and the solution was refluxed for $10 \mathrm{~min}$. Then, 2,9-dimethylhydrazin-1,10-phenanthroline $(134 \mathrm{mg}, 0.5$ mmol) was added as solid in the previous solution and the reflux was pursued another $10 \mathrm{~min}$, followed by the addition of 2,6-diacetylpyridine $(81 \mathrm{mg}, 0.5 \mathrm{mmol}$ ) and 2-3 drops of concentrated $\mathrm{HCl}$ (37\%). The reflux was maintained for $1 \mathrm{~h}$. The light green color of the solution turned to light yellow after 30 min. Addition of an excess of solid $\mathrm{NaBF}_{4}$ and cooling gave yellow microcrystalline powder which was filtered off, washed with water and methanol and dried in vacuum. Single crystals for Xray analysis were obtained by slow evaporation of a $\mathrm{MeOH}$ solution Yield: $70 \%, \sim 230 \mathrm{mg}$. Elemental analysis Calcd for $\mathrm{C}_{23} \mathrm{H}_{25} \mathrm{~B}_{2} \mathrm{~F}_{8} \mathrm{~N}_{7} \mathrm{NiO}_{2}$ : C, 41.62; $\mathrm{H}, 3.79 ; \mathrm{N}, 14.77$ Found: $\mathrm{C}, 41.54 ; \mathrm{H}, 3.54 ; \mathrm{N}, 14.86$. IR $\left(\right.$ ATR, $\mathrm{cm}^{-1}$ ): 3466 (w), 1595 (s), 1574 (s), 1499 (s), 1480 (s), 1425 (s), 1354 (s), 1304 (s), 1251 (s), 1150 $(\mathrm{s}), 1036(\mathrm{w}), 847(\mathrm{~s}), 688(\mathrm{w}), 661(\mathrm{~s}), 522(\mathrm{~s}), 494(\mathrm{~s}), 472(\mathrm{~s})$.

$\left[\left\{\mathrm{NiL}^{\mathrm{NSPhenMe}}\right\}\left\{\mathrm{Ni}(\mathrm{CN})_{4}\right\}\right]_{n} \cdot 0.5 \mathrm{H}_{2} \mathrm{O}(2) .5 \mathrm{~mL}$ of a solution of $\mathrm{K}_{2} \mathrm{Ni}(\mathrm{CN})_{4}(8 \mathrm{mg}, 0.033 \mathrm{mmol})$ in water were placed in a $10 \mathrm{~mL}$ test tube, $5 \mathrm{~mL}$ of a methanol solution of $1(22 \mathrm{mg}, 0.033 \mathrm{mmol}$ ) were carefully added to the top. Yellow single crystals of $\left[\left\{\mathrm{NiL}^{\mathrm{NSPhenMe}}\right\}\left\{\mathrm{Ni}(\mathrm{CN})_{4}\right\}\right]_{\mathrm{n}}$ were formed after 2 days. The crystals were filtered and washed with water, methanol, and dried with diethyl ether. Yield: $25 \%$, 5mg. Elem. anal. Calcd for $\mathrm{C}_{27} \mathrm{H}_{21} \mathrm{~N}_{11} \mathrm{Ni}_{2} \cdot 2 \mathrm{H}_{2} \mathrm{O}: \mathrm{C}, 49.67 ; \mathrm{H}, 3.86 ; \mathrm{N}, 23.60$. Found: $\mathrm{C}, 49.34 ; \mathrm{H}, 3.66 ; \mathrm{N}$, 23.55. IR (ATR, cm ${ }^{-1}$ ): 2152 (s), 2119 (s), 1591 (s), 1575 (s), 1496 (s), 1472 (s), 1417 (s), 1349 (s), 1298 (s), $1247(\mathrm{~s}), 1181(\mathrm{~s}), 1146(\mathrm{~s}), 1088(\mathrm{~s}), 1031(\mathrm{~s}), 954(\mathrm{~s}), 843(\mathrm{~s}), 808(\mathrm{~s}), 788(\mathrm{~s}), 735(\mathrm{~s}), 686$ (s), 658 (s).

$\left[\left\{\mathrm{NiL}^{\mathrm{NSPhenMe}}\right\}\left\{\mathrm{CrL}^{\mathrm{N} 302 \mathrm{Ph}}(\mathrm{CN})_{2}\right\}_{2}\right] \cdot 2 \mathrm{H}_{2} \mathrm{O}$ (3). $\mathrm{K}\left[\mathrm{CrL}^{\mathrm{N} 302 \mathrm{Ph}}(\mathrm{CN})_{2}\right](29 \mathrm{mg}, 0.05 \mathrm{mmol})$ in $10 \mathrm{~mL}$ of water/ethanol solution (1:1) was placed into a test tube, a solution of $1(17 \mathrm{mg}, 0.025 \mathrm{mmol})$ in 10 $\mathrm{mL}$ ethanol was carefully layered on the top. Red crystals of the trinuclear $\left[\left\{\mathrm{Ni}(\mathrm{II}) \mathrm{L}^{\mathrm{NSPhenMe}}\right\}\left\{\mathrm{CrL}^{\mathrm{N}{ }^{\mathrm{NO} 2 \mathrm{Ph}}}(\mathrm{CN})_{2}\right\}_{2}\right]$ complex were formed after 3 days. The tube was left undisturbed until complete diffusion. Dark-orange plate-shaped crystals were then collected, washed with water, ethanol, and dried with diethyl ether. Yield: $49 \%, \sim 40 \mathrm{mg}$. Elem. anal. Calcd for $\mathrm{C}_{73} \mathrm{H}_{63} \mathrm{Cr}_{2} \mathrm{~N}_{21} \mathrm{Ni}_{1} \mathrm{O}_{6}$ 0.5 $\mathrm{H}_{2} \mathrm{O}: \mathrm{C}, 59.08, \mathrm{H}, 4.21, \mathrm{~N}, 19.82$; Found: C, 59.23, H, 4.30, N, 19.56. IR (ATR, $\mathrm{cm}^{-1}$ ): 2965(s), 2143( $\left(\mathrm{v}_{\mathrm{cN}}\right), 1585(\mathrm{~s}), 1560(\mathrm{~s}), 1555(\mathrm{~s}), 1518(\mathrm{~s}), 1491(\mathrm{~s}), 1420(\mathrm{~s}), 1376(\mathrm{~s}), 1341(\mathrm{~s}), 1298(\mathrm{~s}), 1172(\mathrm{~s})$, 1146(s), 1088(s), 1068(s), 1045(s), 993(s), 905(s), 843(s), 807(s), 742(s), 708(s), 681(s), 660(s), 643(s), 579(s), 559(s), 545(s), 470(s).

$\left[\left\{\mathrm{NiL}^{\mathrm{N} 5 \mathrm{PhenMe}}\right\}\left\{\mathrm{CrL}^{\mathrm{N} 302 \mathrm{Ph}}(\mathrm{CN})_{2}\right\}\right] \cdot \mathrm{DMF} \cdot\left[\mathrm{ClO}_{4}\right](4) . \mathrm{K}\left[\mathrm{CrL}^{\mathrm{N3O2Ph}}(\mathrm{CN})_{2}\right](29 \mathrm{mg}, 0.05 \mathrm{mmol})$ in $2 \mathrm{~mL}$ of DMF was slowly added to the solution of $1(35 \mathrm{mg}, 0.053 \mathrm{mmol})$ and $\mathrm{KClO}_{4}(28 \mathrm{mg}, 0.2 \mathrm{mmol})$ in $3 \mathrm{~mL}$ of DMF. After $15 \mathrm{~min}$ of stirring, the solution was left undisturbed. Orange crystals were formed after 5 days of slow evaporation of the solvent. The crystals were carefully washed with water and methanol 
to eliminate the excess of $\mathrm{KClO}_{4}$. Yield: $40 \%, \sim 20 \mathrm{mg}$. Elem. anal. Calcd for $\mathrm{C}_{51} \mathrm{H}_{47} \mathrm{Cl}_{1} \mathrm{Cr}_{1} \mathrm{~N}_{15} \mathrm{Ni}_{1} \mathrm{O}_{7}+$ $2 \mathrm{H}_{2} \mathrm{O}: \mathrm{C}, 52.61, \mathrm{H}, 4.41, \mathrm{~N}, 18.05$; Found: $\mathrm{C}, 52.43, \mathrm{H}, 4.30, \mathrm{~N}, 17.96$. IR (ATR, $\mathrm{cm}^{-1}$ ): $2160\left(\mathrm{w}, \mathrm{v}_{\mathrm{CN}}\right.$ ), 1585 (s), 1557 (s), 1516 (s), 1493 (s), 1419 (s), 1373 (s), 1299 (s), 1173 (s), 1147 (s), 1087-1030 (vs), $993(\mathrm{~s}), 905(\mathrm{~s}), 843(\mathrm{~s}), 802(\mathrm{~s}), 738(\mathrm{~s}), 709(\mathrm{~s}), 682(\mathrm{~s}), 659$ (s), $622(\mathrm{~s}), 583(\mathrm{~s}), 546(\mathrm{~s}), 481(\mathrm{~s})$.

Magnetic properties: Magnetic measurements were carried out with a Quantum Design MPMS-5S SQUID magnetometer on freshly isolated polycrystalline powders mixed with grease and hold in gelatin capsules. Susceptibility data have been collected in a field of $1 \mathrm{kOe}$ (or as stated otherwise) between 300 and $2 \mathrm{~K}$ and corrected for the diamagnetic contribution by using Pascal's tables ${ }^{46}$ and for the sample holder. The field dependences of the magnetization were measured in magnetic fields up to $5 \mathrm{~T}$. AC susceptibility data have been obtained with $\mathrm{H}_{\mathrm{AC}}=3$ Oe for frequencies between 1 and $1500 \mathrm{~Hz}$.

X-ray Diffraction: Data for compound 1, 2, $\mathbf{3}$ and $\mathbf{4}$ were collected at low temperature on a Bruker Apex2 diffractometer equipped with a Mo microfocus source.

For compound [ $\left.\mathrm{NiL}^{\mathrm{N3O2Ph}}\right]_{2}$, data collection was performed at $180 \mathrm{~K}$ on a GEMINI diffractometer using $\mathrm{Cu}-K \alpha$ radiation $(\lambda=1.54180 \AA)$. The structures were solved by SUPERFLIP or by direct methods using SIR92 and refined by means of least-squares procedures on $F$ using CRYSTALS. Atomic scattering factors were taken from the International tables for X-ray Crystallography. Hydrogen atoms were refined using a riding model. Several disorders (especially on ligands) were treated; refinement of the final models led to imperfect but reasonable solutions.

For 2, the ligand was found disordered over two positions in its own plane around N2-Ni1-N1 axis (see Figure S2). The model was obtained with a $0.5: 0.5$ occupancy ratio and a rotation about $9^{\circ}$. For compound 3, measurements on different crystals were performed and despite low temperature (100 $\mathrm{K})$ analyses, the structures always exhibited a general disorder on the ligand around N1-Ni1-N1' axis with $180^{\circ}$ rotation (Figure S4). Constrains were applied and the two moieties have been refined isotropically. Refinement of the used model (atoms with a 0.5 or 1 occupancy) led to to an imperfect but reasonable solution despite $\mathrm{R}$ factor around $10 \%$. For compound $\mathbf{4}$, it was not possible to resolve diffuse electron-density residuals (enclosed disordered water and DMF solvent molecules). Treatment with the SQUEEZE facility from PLATON resulted in a smooth refinement.

Crystallographic information for all the complexes is gathered in Table S1 (SI). ORTEP plots of the asymmetric units and selected bond distances and angles are given in the supporting information. The cif have been deposited at The Cambridge Crystallographic Data Centre under the references CCDC 1957997-1958001; they can be obtained from www.ccdc.cam.ac.uk/data request/cif.

The powder X-ray diffraction (PXRD) patterns were recorded in transmission mode using capillary tubes on a XPert Pro (Theta-Theta mode) Panalytical diffractometer with $\lambda\left(\mathrm{Cu}_{\mathrm{K} \alpha 1, \mathrm{k} \alpha 2}\right)=1.54059$ and $1.54439 \AA$ A. 


\section{REFERENCES}

1. O. Waldmann, A criterion for the anisotropy barrier in single-molecule magnets, Inorg. Chem., 2007, 46, 10035-10037.

2. S. Gomez-Coca, E. Cremades, N. Aliaga-Alcalde and E. Ruiz, Mononuclear Single-Molecule Magnets: Tailoring the Magnetic Anisotropy of First-Row Transition-Metal Complexes, J. Am. Chem. Soc., 2013, 135, 7010-7018.

3. A. K. Bar, C. Pichon and J.-P. Sutter, Magnetic anisotropy in two- to eight-coordinated transitionmetal complexes: Recent developments in molecular magnetism, Coord. Chem. Rev., 2016, 308, 346-380.

4. R. Ruamps, L. J. J. Batchelor, R. Maurice, N. Gogoi, P. Jiménez-Lozano, N. Guihéry, C. de Graaf, A.L. Barra, J.-P. Sutter and T. Mallah, Origin of the Magnetic Anisotropy in Ni(II) and Co(II) Heptacoordinate Complexes, Chem. Eur. J., 2013, 19, 950-957.

5. B. Drahoš, R. Herchel and Z. Trávníček, Structural, Magnetic, and Redox Diversity of First-Row Transition Metal Complexes of a Pyridine-Based Macrocycle: Well-Marked Trends Supported by Theoretical DFT Calculations, Inorg. Chem., 2015, 54, 3352-3369.

6. A. K. Bar, C. Pichon, N. Gogoi, C. Duhayon, S. Ramasesha and J.-P. Sutter, Single-ion magnet behaviour of heptacoordinated $\mathrm{Fe}(\mathrm{II})$ complexes: on the importance of supramolecular organization, Chem. Comm., 2015, 51, 3616-3619.

7. P. Antal, B. Drahoš, R. Herchel and Z. Trávníček, Late First-Row Transition-Metal Complexes Containing a 2-Pyridylmethyl Pendant-Armed 15-Membered Macrocyclic Ligand. Field-Induced Slow Magnetic Relaxation in a Seven-Coordinate Cobalt(II) Compound, Inorg. Chem., 2016, 55, 5957-5972.

8. P. Antal, B. Drahoš, R. Herchel and Z. Trávníček, Structure and Magnetism of Seven-Coordinate FellI, Fell, Coll and Nill Complexes Containing a Heptadentate 15-Membered Pyridine-Based Macrocyclic Ligand, Eur. J. Inorg. Chem., 2018, , 4286-4297.

9. Y.-F. Deng, B. Yao, P.-Z. Zhan, D. Gan, Y.-Z. Zhang and K. R. Dunbar, Synthesis and magnetic studies of pentagonal bipyramidal metal complexes of $\mathrm{Fe}$, Co and Ni, Dalton Trans., 2019, 48, 3243-3248.

10. L. J. Batchelor, M. Sangalli, R. Guillot, N. Guihéry, R. Maurice, F. Tuna and T. Mallah, Pentanuclear Cyanide-Bridged Complexes Based on Highly Anisotropic Coll Seven-Coordinate Building Blocks: Synthesis, Structure, and Magnetic Behavior, Inorg. Chem., 2011, 50, 12045.

11. M. Dey, S. Dutta, B. Sarma, R. C. Deka and N. Gogoi, Modulation of the coordination environment: a convenient approach to tailor magnetic anisotropy in seven coordinate Co(ii) complexes, Chem. Comm., 2016, 52, 753-756.

12. B. Drahoš, R. Herchel and Z. Trávníček, Impact of Halogenido Coligands on Magnetic Anisotropy in Seven-Coordinate Co(II) Complexes, Inorg. Chem., 2017, 56, 5076-5088.

13. X.-C. Huang, C. Zhou, D. Shao and X.-Y. Wang, Field-Induced Slow Magnetic Relaxation in Cobalt(II) Compounds with Pentagonal Bipyramid Geometry, Inorg. Chem., 2014, 53, 1267112673.

14. A. K. Mondal, A. Mondal, B. Dey and S. Konar, Influence of the Coordination Environment on Easy-Plane Magnetic Anisotropy of Pentagonal Bipyramidal Cobalt(II) Complexes, Inorg. Chem., 2018, 57, 9999-10008.

15. D. Shao, S.-L. Zhang, L. Shi, Y.-Q. Zhang and X.-Y. Wang, Probing the Effect of Axial Ligands on Easy-Plane Anisotropy of Pentagonal-Bipyramidal Cobalt(II) Single-lon Magnets, Inorg. Chem., 2016, 55, 10859-10869.

16. E. L. Gavey and M. Pilkington, Coordination complexes of 15-membered pentadentate aza, oxoaza and thiaaza Schiff base macrocycles "Old Complexes Offer New Attractions", Coord. Chem. Rev., 2015, 296, 125-152.

17. Y.-Z. Zhang, B.-W. Wang, O. Sato and S. Gao, First Fe(II)-based cyano-bridged single molecule magnet $\left[\mathrm{CrIIIFell}_{2}\right]$ with a large anisotropy, Chem. Comm., 2010, 46, 6959-6961. 
18. T. S. Venkatakrishnan, S. Sahoo, N. Bréfuel, C. Duhayon, C. Paulsen, A.-L. Barra, S. Ramasesha and J.-P. Sutter, Enhanced Ion Anisotropy by Nonconventional Coordination Geometry: Single-Chain Magnet Behavior for a $\left[\left\{\mathrm{Fe}^{\mathrm{II}} \mathrm{L}\right\}_{2}\left\{\mathrm{Nb}^{\mathrm{IV}}(\mathrm{CN})_{8}\right\}\right]$ Helical Chain Compound Designed with Heptacoordinate Fe", J. Am. Chem. Soc., 2010, 132, 6047-6056.

19. N. Gogoi, M. Thlijeni, C. Duhayon and J.-P. Sutter, Heptacoordinated Nickel(II) as an Ising-Type Anisotropic Building Unit: Illustration with a Pentanuclear $\left[(\mathrm{NiL})_{3}\left\{\mathrm{~W}(\mathrm{CN})_{8}\right\}_{2}\right]$ Complex, Inorg. Chem., 2013, 52, 2283-2285.

20. D. Shao, X.-H. Zhao, S.-L. Zhang, D.-Q. Wu, X.-Q. Wei and X.-Y. Wang, Structural and magnetic tuning from a field-induced single-ion magnet to a single-chain magnet by anions, Inorg. Chem. Front., 2015, 2, 846-853.

21. B. Drahoš, R. Herchel and Z. Trávníček, Single-Chain Magnet Based on 1D Polymeric AzidoBridged Seven-Coordinate Fe(II) Complex with a Pyridine-Based Macrocyclic Ligand, Inorg. Chem., 2018, 57, 12718-12726.

22. C. Pichon, N. Suaud, C. Duhayon, N. Guihéry and J.-P. Sutter, Cyano-Bridged Fe(II)-Cr(III) SingleChain Magnet Based on Pentagonal Bipyramid Units: On the Added Value of Aligned Axial Anisotropy, J. Am. Chem. Soc., 2018, 140, 7698-7704.

23. M. Regueiro-Figueroa, L. M. P. Lima, V. Blanco, D. Esteban-Gómez, A. de Blas, T. Rodríguez-Blas, R. Delgado and C. Platas-Iglesias, Reasons behind the Relative Abundances of Heptacoordinate Complexes along the Late First-Row Transition Metal Series, Inorg. Chem., 2014, 53, 1285912869.

24. C. W. G. Ansell, J. Lewis, M. C. Liptrot, P. R. Raithby and M. Schröder, The stabilisation of low oxidation state transition metal complexes. Preparation and electrochemistry of cobalt(II) unsaturated macrocyclic complexes and the stabilisation of a cobalt $(\mathrm{I})$ derivative. Crystal and molecular structures of $\left[\mathrm{Co}(\mathrm{L})\left(\mathrm{CH}_{3} \mathrm{OH}\right)_{2}\right]\left[\mathrm{BF}_{4}\right]_{2}$ and $\left[\mathrm{Co}(\mathrm{L})\left\{\mathrm{P}\left(\mathrm{OCH}_{3}\right)_{3}\right\}\right]\left[\mathrm{BF}_{4}\right]$, J. Chem. Soc. Dalton Trans., 1982, , 1593-1601.

25. M. M. Bishop, J. Lewis, T. D. O'Donoghue, P. R. Raithby and J. N. Ramsden, X-Ray crystal structure of a planar, high-spin iron(II) complex of a pentadentate unsaturated macrocycle formed by reaction of 2,9-di(1-methylhydrazino)1,10-phenanthroline monohydrochloride with 2,6diacetylpyridine, J. Chem. Soc. Chem. Comm., 1978, , 828-829.

26. M. M. Bishop, J. Lewis, T. D. O'Donoghue, P. R. Raithby and J. N. Ramsden, Chemistry of polydentate ligands. Part 8. Preparation and properties of iron(II) complexes with quinquedentate macrocyclic ligands. Crystal and molecular structure of a compound where highspin Fe sits in the ligand cavity. Electrochemistry of a series of complexes with the macrocycles, $J$. Chem. Soc. Dalton Trans., 1980, , 1390-1396.

27. L. Y. Chung, E. C. Constable, M. S. Khan, J. Lewis, P. R. Raithby and M. D. Vargas, Structural characterisation of a pentagonal bipyramidal macrocyclic chromium(III) complex; an explanation of a chromium-mediated 'transient-template' effect, J. Chem. Soc. Chem. Comm., 1984, , 14251426.

28. J. Lewis, T. D. O'Donoghue and P. R. Raithby, Chemistry of polydentate ligands. Part 7. Synthesis, characterisation, and properties of some manganese(II) complexes of quinquedentate macrocyclic ligands based on 1,10-phenanthroline. Crystal and molecular structure of a complex with pentagonal-pyramidal coordination geometry about the Mn, J. Chem. Soc. Dalton Trans., 1980, , 1383-1389.

29. C. W. G. Ansell, J. Lewis, P. R. Raithby, J. N. Ramsden and M. Schroder, X-Ray crystal structure of the pentagonal bipyramidal nickel(II) complex $\left[\mathrm{Ni}(\mathrm{L})\left(\mathrm{H}_{2} \mathrm{O}\right)_{2}\right]\left(\mathrm{BF}_{4}\right)_{2}$ and the selective stabilisation of the nickel(I) oxidation state by a quinquedentate macrocyclic ligand, J. Chem. Soc. Chem. Comm., 1982, , 546-547.

30. C. Pichon, B. Elrez, V. Béreau, C. Duhayon and J.-P. Sutter, From Heptacoordinated Crlll Complexes with Cyanide or Isothiocyanate Apical Groups to 1D Heterometallic Assemblages with All-Pentagonal-Bipyramid Coordination Geometries, Eur. J. Inorg. Chem., 2018, 2018, 340-348. 
31. M. Llunell, D. Casanova, J. Cirera, P. Alemany and S. Alvarez, SHAPE: Program for the stereochemical analysis of molecular fragments by means of continuous shape measures and associated tools.Journal, 2013.

32. D. Casanova, P. Alemany, J. M. Bofill and S. Alvarez, Shape and symmetry of heptacoordinated transition-metal complexes: structural trends, Chem. Eur. J., 2003, 9, 1281-1295.

33. S. Haldar, R. Raghunathan, J.-P. Sutter and S. Ramasesha, Modelling magnetic anisotropy of single-chain magnets in $|d / J| \geq 1$ regime, Mol. Phys., 2017, 115, 2849-2859.

34. R. Ruamps, R. Maurice, C. de Graaf and N. Guihéry, Interplay between Local Anisotropies in Binuclear Complexes, Inorg. Chem., 2014, 53, 4508-4516.

35. N. F. Chilton, R. P. Anderson, L. D. Turner, A. Soncini and K. S. Murray, PHI: A powerful new program for the analysis of anisotropic monomeric and exchange-coupled polynuclear $d$ - and $f$ block complexes, J. Comput. Chem., 2013, 34, 1164-1175.

36. A. K. Bar, N. Gogoi, C. Pichon, V. M. L. D. P. Goli, M. Thlijeni, C. Duhayon, N. Suaud, N. Guihéry, A.L. Barra, S. Ramasesha and J.-P. Sutter, Pentagonal Bipyramid Fe" Complexes: Robust Ising-Spin Units towards Heteropolynuclear Nanomagnets, Chem. Eur. J., 2017, 23, 4380-4396.

37. T. Mallah, C. Auberger, M. Verdaguer and P. Veillet, A heptanuclear $\mathrm{Cr}^{\prime \prime \prime} \mathrm{Ni}^{\prime \prime}{ }_{6}$ complex with a lowlying $S=15 / 2$ ground state, J. C. S. Chem. Commun., 1995, 61.

38. V. Marvaud, C. Decroix, A. Scuiller, F. Tuyèras, C. Guyard-Duhayon, J. Vaissermann, J. Marrot, F. Gonnet and M. Verdaguer, Hexacyanometalate molecular chemistry: di-, tri-, tetra-, hexa-, and heptanuclear heterobimetallic complexes, control of nuclearity and structural anisotropy, Chem. Eur. J., 2003, 9, 1692-1705.

39. M. Drillon, E. Coronado, D. Beltran and R. Georges, Chem. Phys., 1983, 79, 449.

40. R. Georges, J. J. Borras-Almenar, E. Coronado, J. Curély and M. Drillon, in Magnetism: Molecules to materials: Models and experiments, ed. M. Miller; J.S. and Drillon, Wiley-VCH, Weinheim, 2002, vol. 1, ch. 1, pp. 1-47.

41. R. J. Glauber, Time-Dependent Statistics of the Ising Model, J. Math. Phys., 1963, 4, 294-307.

42. C. Coulon, R. Clérac, L. Lecren, W. Wernsdorfer and H. Miyasaka, Glauber dynamics in a singlechain magnet: from theory to real systems, Phys. Rev. B, 2004, 69, 132408.

43. C. Coulon, V. Pianet, M. Urdampilleta and R. Clérac, in Molecular Nanomagnets and Related Phenomena, ed. S. Gao, Springer Berlin Heidelberg, 2015, vol. 164, ch. 154, pp. 143-184.

44. H. C. Guo, R. H. Zheng and H. J. Jiang, Improved Synthesis of 2,9-Dichloro-1,10-phenanthroline, Org. Prep. Proc. Inter., 2012, 44, 392-396.

45. J. Lewis and T. D. O'Donoghue, Chemistry of polydentate ligands. Part 5. Complexes of 2,9-dihydrazino-derivatives of 1,10-phenanthroline. Dependence of co-ordination number of a ligand on the anion present, Journal of the Chemical Society, Dalton Transactions, 1980, DOI: 10.1039/DT9800000736, 736-742.

46. O. Kahn, Molecular Magnetism, VCH, Weinheim, 1993. 


\section{CONTENT :}

Table S1 Crystallographic data for 1-4 and [NiL $\left.{ }^{\mathrm{N3O2Ph}}\right]_{2}$

Table S2 Results from the polyhedral shape analysis by SHAPE $^{1}$ for the heptacoordinated metal centers in 1-4.

Figure S1 $\left[\mathrm{NiL}^{\mathrm{N} 302 \mathrm{Ph}}\right]_{2}$ : molecular structure and selected bond distances $(\AA)$ and angles $\left({ }^{\circ}\right)$.

Figure $\mathrm{S2}\left[\mathrm{NiL}^{\mathrm{N} S \mathrm{PhenMe}}\left(\mathrm{H}_{2} \mathrm{O}\right)_{2}\right] \cdot 2 \mathrm{BF}_{4}, 1$ : ORTEP view of the asymmetric unit and crystal packing.

Figure S3 $\left[\left\{\mathrm{NiL}^{\mathrm{NSPhenMe}}\right\}\left\{\mathrm{Ni}(\mathrm{CN})_{4}\right\}\right] 0.5 \mathrm{H}_{2} \mathrm{O}, 2$ : ORTEP view of the asymmetric and crystal packing.

Figure S4 $\left[\left\{\mathrm{NiL}^{\mathrm{N} 5 \mathrm{Ph} h \mathrm{nMe}}\right\}\left\{\mathrm{CrL}^{\mathrm{N} 302 \mathrm{Ph}}(\mathrm{CN})_{2}\right\}_{2}\right] .2 \mathrm{H}_{2} \mathrm{O}$, 3. (a) detail of the disordered $\mathrm{L}^{\mathrm{N} 5 \mathrm{Ph} e n \mathrm{Me}}$ ligand and best modeling, (b) ORTEP plots of asymmetric unit, (c) crystal packing.

Figure S5 Powder X-Ray patterns for $\left[\left\{\mathrm{NiL}^{\mathrm{NSPhenMe}}\right\}\left\{\mathrm{CrL}^{\mathrm{N}}{ }^{\mathrm{NO} 2 \mathrm{Ph}}(\mathrm{CN})_{2}\right\}_{2}\right] \cdot 2 \mathrm{H}_{2} \mathrm{O}, \mathbf{3}$

Figure S6 $\left[\left\{\mathrm{NiL}^{\mathrm{NPPhenMe}}\right\}\left\{\mathrm{CrL}^{\mathrm{N} 302 \mathrm{Ph}}(\mathrm{CN})_{2}\right\}\right] \cdot \mathrm{dmf}^{\mathrm{C}} \mathrm{ClO}_{4}$, 4: (a) ORTEP plot of asymmetric unit, (b) Crystal packing, (c) inter-chain arrangement and relative organization of the $\mathrm{Ni}$ moieties

Figure S7 Powder X-Ray patterns for $\left[\left\{\mathrm{NiL}^{\mathrm{NSPhenMe}}\right\}\left\{\mathrm{CrL}^{\mathrm{N} 302 \mathrm{Ph}}(\mathrm{CN})_{2}\right\}\right] \cdot \mathrm{dmf} \cdot \mathrm{ClO}_{4}, 4$

Figure 58 Magnetic behavior for $\left[\mathrm{NiL}^{\mathrm{NSPhenMe}}\left(\mathrm{H}_{2} \mathrm{O}\right)_{2}\right] \cdot 2 \mathrm{BF}_{4}, 1$. Experimental $(\mathrm{O})$ and calculated (-) temperature dependence of $\chi_{M} T$, and isothermal magnetizations.

Figure S9 Additional magnetic data for $\left[\left\{\mathrm{NiL}^{\mathrm{NSPhenMe}}\right\}\left\{\mathrm{CrL}^{\mathrm{N3O2Ph}}(\mathrm{CN})_{2}\right\}\right] \cdot \mathrm{dmf} \cdot \mathrm{ClO}_{4}, 4$ 
Table S1 Crystallographic data for 1-4 and $\left[\mathrm{NiL}^{\mathrm{N3O2Ph}}\right]_{2}$

\begin{tabular}{|c|c|c|c|c|c|}
\hline & {$\left[\mathrm{NiL}^{\mathrm{N3O2Ph}}\right]_{2}$} & 1 & 2 & 3 & 4 \\
\hline Formula & $\mathrm{C}_{46} \mathrm{H}_{38} \mathrm{~N}_{10} \mathrm{Ni}_{2} \mathrm{O}_{4}$ & $\mathrm{C}_{23} \mathrm{H}_{25} \mathrm{~B}_{2} \mathrm{~F}_{8} \mathrm{~N}_{7} \mathrm{Ni}_{1} \mathrm{O}_{2}$ & $\mathrm{C}_{27} \mathrm{H}_{22} \mathrm{~N}_{11} \mathrm{Ni}_{2} \mathrm{O}_{0.50}$ & $\mathrm{C}_{73} \mathrm{H}_{63} \mathrm{Cr}_{2} \mathrm{~N}_{21} \mathrm{Ni}_{1} \mathrm{O}_{6}$ & $\mathrm{C}_{51} \mathrm{H}_{47} \mathrm{Cl}_{1} \mathrm{Cr}_{1} \mathrm{~N}_{15} \mathrm{Ni}_{1} \mathrm{O}_{7}$ \\
\hline Mr & 912.24 & 663.81 & 625.97 & 1493.14 & 1128.19 \\
\hline Crystal system & monoclinic & monoclinic & monoclinic & monoclinic & monoclinic \\
\hline Crystal color & red & orange & yellow & orange & orange \\
\hline Space group & $\mathrm{C} 2 / \mathrm{c}$ & $\mathrm{P} 21 / \mathrm{c}$ & $\mathrm{P} 2{ }_{1} / \mathrm{n}$ & $\mathrm{P} 2{ }_{1} / \mathrm{n}$ & $\mathrm{C} 2 / \mathrm{c}$ \\
\hline$a / \AA$ & $22.4352(6)$ & $14.874(1)$ & $10.2821(5)$ & $11.5125(3)$ & $28.021(2)$ \\
\hline b/Å & $16.1038(2)$ & $11.9090(9)$ & $17.4266(7)$ & $16.4374(3)$ & $20.6609(10) \AA$ \\
\hline$c / \AA$ & $15.4417(4)$ & $15.814(1)$ & $14.9144(6)$ & $19.5359(4)$ & $20.235(1)$ \\
\hline$\alpha /^{\circ}$ & 90 & 90 & 90 & 90 & 90 \\
\hline $\boldsymbol{\beta} /{ }^{\circ}$ & $133.251(5)$ & $109.989(3)$ & $102.068(2)$ & $106.980(2)$ & $96.273(2)$ \\
\hline$\gamma /^{\circ}$ & 90 & 90 & 90 & 90 & 90 \\
\hline$V / \AA^{3}$ & $4063.5(4)$ & $2632.4(4)$ & $2613.3(2)$ & $3535.7(1)$ & $11644(1)$ \\
\hline$Z$ & 4 & 4 & 4 & 2 & 8 \\
\hline $\mathbf{T} / \mathbf{K}$ & 180 & 107 & 100 & 100 & 100 \\
\hline$\rho_{\text {calcd }} / \mathrm{gcm}^{-1}$ & 1.49 & 1.67 & 1.59 & 1.40 & 1.29 \\
\hline$\mu(\mathbf{M o}-\mathrm{K} \alpha) \mathbf{m m}^{-1}$ & 1.637 & 0.832 & 1.484 & 0.634 & 0.616 \\
\hline Reflections measured & 18728 & 55103 & 55318 & 104637 & 148165 \\
\hline $\begin{array}{l}\text { Independent } \\
\text { reflect. (Rint) }\end{array}$ & $3025(0.030)$ & $6533(0.052)$ & $6471(0.059)$ & $11367(0.115)$ & $13403(0.074)$ \\
\hline Refl. with I > n $\sigma(I)$ & $2813, \mathrm{n}=1.5$ & $5008, n=3$ & $4536, n=3$ & $8067, n=3$ & $9260, n=3$ \\
\hline $\mathrm{Nb}$ restraints & 0 & 0 & 154 & 0 & 0 \\
\hline Nb parameters & 280 & 388 & 321 & 418 & 676 \\
\hline $\begin{array}{l}\mathbf{R}_{1} / \mathbf{w} \mathbf{R}_{2} \\
(\mathbf{I}>\mathbf{n} \sigma(\mathbf{I}))\end{array}$ & $0.028 / 0.027$ & $0.049 / 0.050$ & $0.072 / 0.076$ & $0.101 / 0.111$ & $0.069 / 0.073$ \\
\hline $\begin{array}{l}\text { Residual e- density } \\
\left(\overline{\mathbf{e}} . \AA^{-3}\right)\end{array}$ & $0.29 /-0.28$ & $1,53 /-1,37$ & $2,15 /-0,93$ & $2.09 /-1.52$ & $1.44 /-1.27$ \\
\hline $\mathrm{CCDC} \mathrm{N}^{\circ}$ & 1957997 & 1958001 & 1958000 & 1957999 & 1957998 \\
\hline
\end{tabular}

Table S2 Results from the polyhedral shape analysis by SHAPE ${ }^{2}$ for the heptacoordinated metal centers in 1-4.

\begin{tabular}{|c|c|}
\hline Complexes & PBPY- $7^{3}$ \\
\hline$\left[\mathrm{NiL}^{\mathrm{N} 5 \text { PhenMe }}\left(\mathrm{H}_{2} \mathrm{O}\right)_{2}\right]\left[\mathrm{BF}_{4}\right]_{2}(\mathbf{1})$ & 0.383 \\
\hline$\left[\left\{\mathrm{NiL}^{\mathrm{N} 5 \mathrm{PhenMe}}\right\}\left\{\mathrm{Ni}(\mathrm{CN})_{4}\right\}\right]_{\mathrm{n}} 0.5 \mathrm{H}_{2} \mathrm{O}(2)$ & 0.302 \\
\hline \multirow[t]{2}{*}[\{\mathrm{NiL}^{\mathrm{N}5\mathrm{PhenMe}}\}\{\mathrm{CrL}^{\mathrm{N}3\mathrm{O}2\mathrm{Ph}}(\mathrm{CN})_{2}\}_{2}]{$\cdot 2 \mathrm{H}_{2} \mathrm{O}(\mathbf{3})$} & Ni: 0.445 \\
\hline & Cr: 0.371 \\
\hline \multirow[t]{2}{*}[\{\mathrm{NiL}^{\mathrm{N}5\mathrm{PhenMe}}\}\{\mathrm{CrL}^{\mathrm{N}3\mathrm{O}2\mathrm{Ph}}(\mathrm{CN})_{2}\}]{$\cdot \mathrm{dmf} \cdot \mathrm{ClO}_{4}(4)$} & Ni: 0.469 \\
\hline & Cr: 0.298 \\
\hline
\end{tabular}

\footnotetext{
${ }^{2}$ SHAPE: Program for the stereochemical analysis of molecular fragments by means of continuous shape measures and associated tools; M. Llunell, D. Casanova, J. Cirera, P. Alemany, S. Alvarez, 2.1 ed., University of Barcelona, Barcelona, 2013.

${ }^{3}$ D. Casanova, P. Alemany, J. M. Bofill, S. Alvarez, Chem. Eur. J. 2003, 9, 1281-1295. PBPY for pentagonal bipyramid
} 
Figure S1 $\left[\mathrm{NiL}^{\mathrm{N} 3 \mathrm{O} 2 \mathrm{Ph}}\right]_{2}$ : Molecular structure.
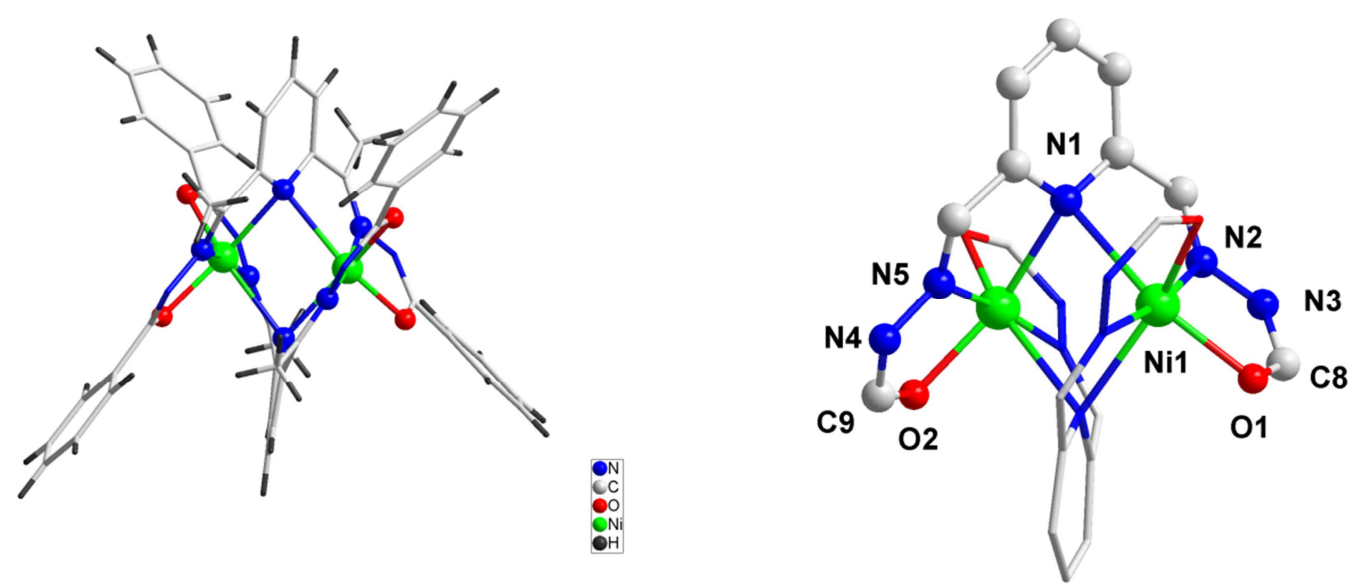

Selected bond distances $(\AA \AA)$ and angles $\left({ }^{\circ}\right)$.

\begin{tabular}{|c|c|c|c|c|c|}
\hline \multirow[t]{6}{*}{$\mathrm{Ni1}$} & $\mathrm{N} 2$ & $1.956(1)$ & N3 & $\mathrm{C} 8$ & $1.330(2)$ \\
\hline & $N 5^{1-x, y, 1.5-z}$ & $1.964(1)$ & N4 & $\mathrm{C9}$ & $1.338(3)$ \\
\hline & $\mathrm{O} 2^{1-x, y, 1.5-z}$ & $2.019(2)$ & $\mathrm{O} 2$ & $\mathrm{C9}$ & $1.274(2)$ \\
\hline & 01 & $2.0263(9)$ & 01 & $\mathrm{C} 8$ & $1.283(2)$ \\
\hline & $N 1^{1-x, y, 1.5-z}$ & $2.291(2)$ & \multirow{2}{*}{\multicolumn{2}{|c|}{$\mathrm{Ni}-\mathrm{N} 1-\mathrm{Ni}^{1-x, y, 1.5-z}$}} & $81.26(4)$ \\
\hline & N1 & $2.414(1)$ & & & \\
\hline N2 & N3 & $1.381(2)$ & \multicolumn{2}{|c|}{ N3-C8-O1, } & $126.1(1)$ \\
\hline N4 & N5 & $1.383(2)$ & \multicolumn{2}{|c|}{ N4-C9-O2, } & $125.8(1)$ \\
\hline
\end{tabular}


Figure $\mathrm{S2}\left[\mathrm{NiL}^{\mathrm{N} 5 \mathrm{PhenMe}}\left(\mathrm{H}_{2} \mathrm{O}\right)_{2}\right] \cdot 2 \mathrm{BF}_{4}, \mathbf{1}$ : ORTEP view of the asymmetric unit (ellipsoids are drawn at $50 \%$ probability level) and crystal packing.
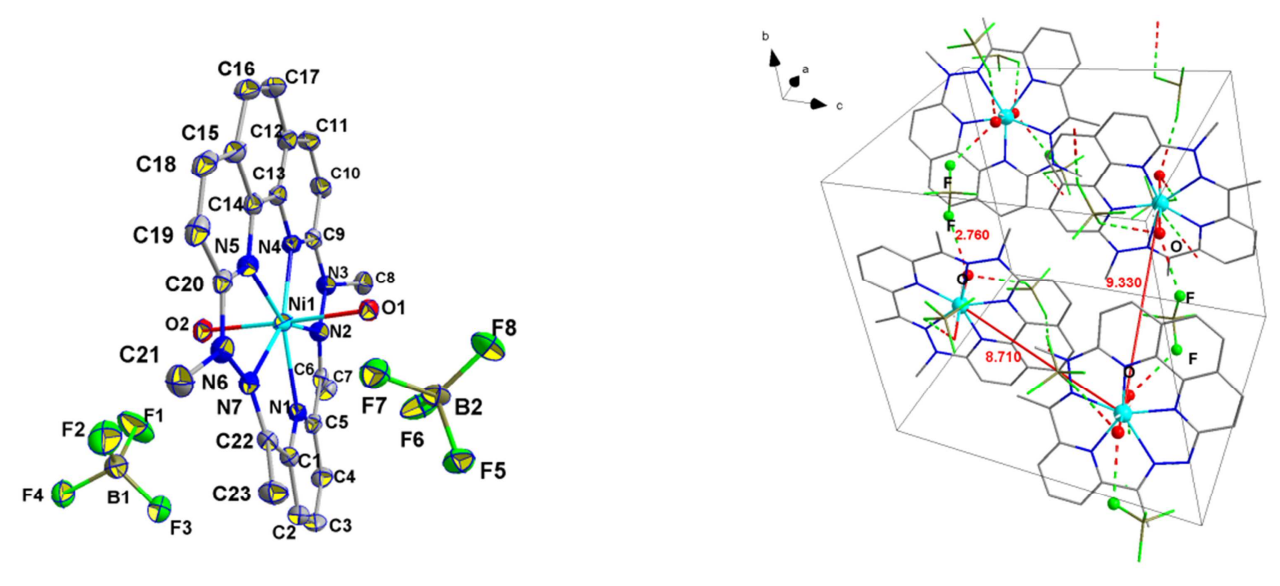

Selected bond distances (Å)

\begin{tabular}{|c|c|c|c|c|c|c|c|c|}
\hline \multirow[t]{7}{*}{$\mathrm{Ni1}$} & N4 & $2.030(2)$ & N2 & N4 & $2.508(3)$ & N5 & C13 & $2.363(3)$ \\
\hline & $\mathrm{O} 2$ & $2.080(2)$ & & $\mathrm{C7}$ & $2.516(3)$ & & C19 & $2.392(3)$ \\
\hline & 01 & $2.098(2)$ & & N1 & $2.605(3)$ & & C15 & $2.424(4)$ \\
\hline & N5 & $2.123(2)$ & N3 & N2 & $1.385(3)$ & & N7 & $2.522(3)$ \\
\hline & N1 & $2.132(2)$ & & C9 & $1.392(3)$ & & N4 & $2.627(3)$ \\
\hline & N2 & $2.213(2)$ & & $\mathrm{C} 8$ & $1.472(3)$ & & C18 & $2.763(3)$ \\
\hline & N7 & $2.434(2)$ & & N4 & $2.306(3)$ & N6 & N7 & $1.362(3)$ \\
\hline \multirow[t]{9}{*}{ N1 } & $\mathrm{C} 1$ & $1.336(3)$ & & $\mathrm{C} 6$ & 2.358431 & & C20 & $1.385(3)$ \\
\hline & $\mathrm{C} 5$ & $1.352(3)$ & & C10 & $2.469(3)$ & & C21 & $1.474(3)$ \\
\hline & $\mathrm{C} 2$ & $2.381(3)$ & N4 & $\mathrm{C} 9$ & $1.312(3)$ & & N5 & $2.302(1)$ \\
\hline & $\mathrm{C} 4$ & $2.390(3)$ & N4 & C13 & $1.361(3)$ & & $\mathrm{C} 22$ & $2.355(2)$ \\
\hline & $\mathrm{C} 22$ & $2.403(3)$ & & N3 & $2.306(3)$ & & C19 & $2.461(3)$ \\
\hline & C6 & $2.427(3)$ & & C14 & $2.362(3)$ & N7 & $\mathrm{C} 22$ & $1.274(3)$ \\
\hline & N7 & $2.591(3)$ & & C10 & $2.384(3)$ & & N6 & $1.362(3)$ \\
\hline & N2 & $2.6055(30)$ & & C12 & $2.415(3)$ & & $\mathrm{C} 20$ & $2.297(3)$ \\
\hline & $\mathrm{C} 3$ & $2.755(3)$ & & N2 & $2.508(3)$ & & $\mathrm{C} 1$ & $2.301(3)$ \\
\hline \multirow[t]{5}{*}{ N2 } & $\mathrm{C} 6$ & $1.279(3)$ & & N5 & $2.627(3)$ & & C21 & $2.508(3)$ \\
\hline & N3 & $1.385(3)$ & & C11 & $2.750(3)$ & & $\mathrm{C} 23$ & $2.513(3)$ \\
\hline & $\mathrm{C} 9$ & $2.299(3)$ & N5 & C20 & $1.320(3)$ & & N5 & $2.522(3)$ \\
\hline & C5 & $2.305(3)$ & & C14 & $1.358(3)$ & & N1 & $2.591(3)$ \\
\hline & $\mathrm{C} 8$ & $2.493(3)$ & & N6 & $2.302(3)$ & & & \\
\hline
\end{tabular}

Figure S3 $\left[\left\{\mathrm{NiL}^{\mathrm{N} 5 \mathrm{PhenMe}}\right\}\left\{\mathrm{Ni}(\mathrm{CN})_{4}\right\}\right] 0.5 \mathrm{H}_{2} \mathrm{O}, 2$ : ORTEP view of the asymmetric unit (ellipsoids are drawn at $50 \%$ probability level) and crystal packing. 

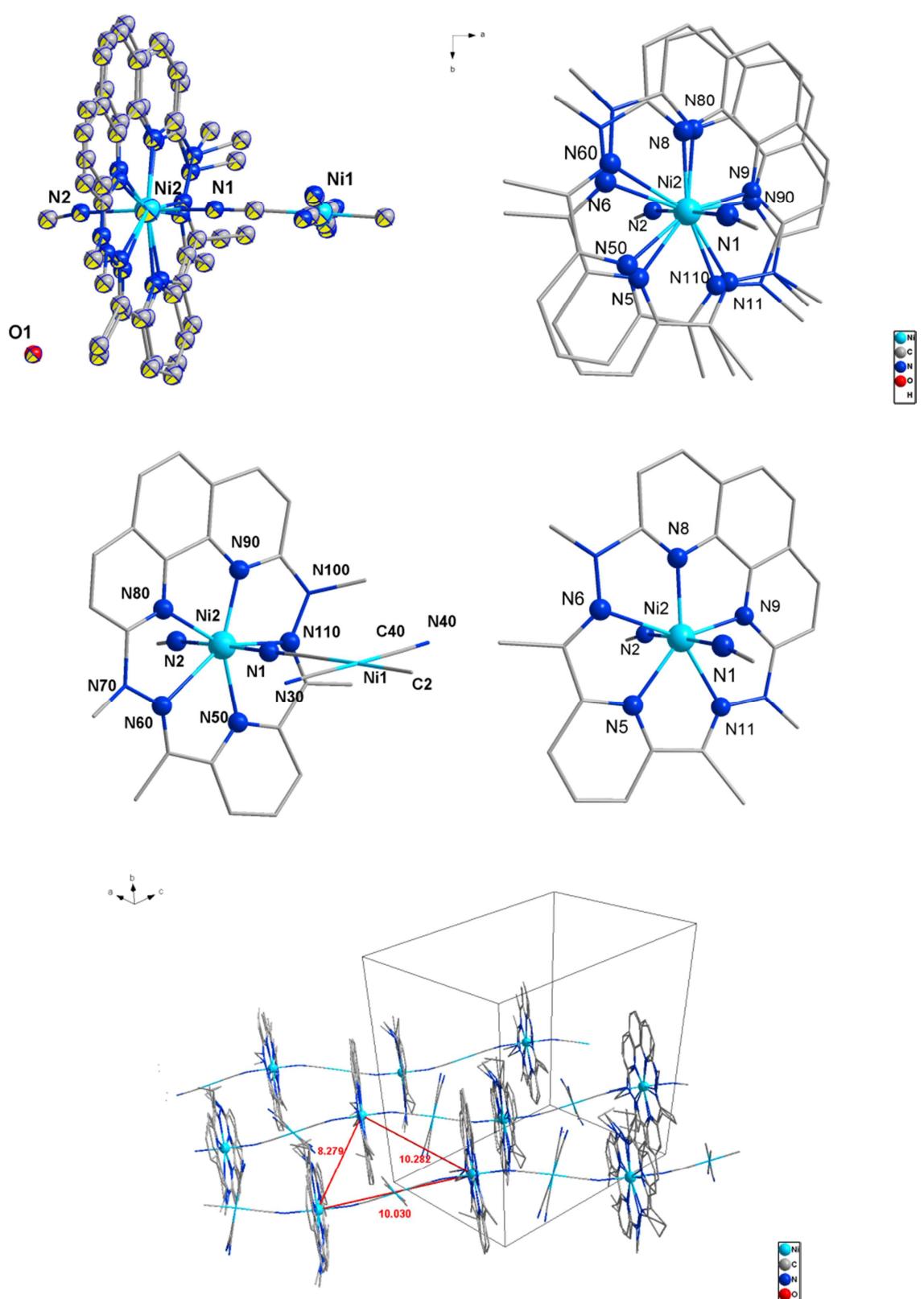

Selected bond distances $(\AA)$ and angles $\left({ }^{\circ}\right)$

$\begin{array}{lll}\text { Ni2 } & \text { N90 } & 2.0387(64) \\ & \text { N1 } & 2.0462(48) \\ \text { N9 } & 2.0614(63) \\ \text { N2 } & 2.0638(48) \\ \text { N8 } & 2.0986(53) \\ \text { N50 } & 2.1475(91) \\ \text { N80 } & 2.1614(36) \\ \text { N110 } & 2.1624(56) \\ \text { N5 } & 2.1703(100)\end{array}$

\begin{tabular}{|c|c|c|}
\hline \multirow[t]{2}{*}{$\mathrm{Ni} 2$} & $2.2621(5$ & \\
\hline & 2.393216 & \\
\hline \multirow{4}{*}{$\mathrm{Ni} 2$} & $2.4846(5$ & \\
\hline & $\mathrm{Ni}^{-0.5+x, 0.5-y,-0.5+z}$ & $8.2785(9)$ \\
\hline & $\mathrm{Ni} 2^{0.5+x, 0.5-y, 0.5+z}$ & $8.2785(9)$ \\
\hline & $\mathrm{Ni}^{2}{ }^{0.5+x, 0.5-y,-0.5+z}$ & $10.0297(11)$ \\
\hline N1-Ni2-N2, & $177.7(2)$ & \\
\hline $\begin{array}{l}\text { 1-N1-Ni2, } \\
1-\mathrm{N2}^{0.5+\times, 0.0}\end{array}$ & $\begin{array}{l}166.1(2) \\
{ }^{5+z}-\mathrm{Ni2}^{0.5+x, 0.5-y,-0.5+}\end{array}$ & \\
\hline
\end{tabular}


Figure S4 $\left[\left\{\mathrm{NiL}^{\mathrm{NSPhenMe}}\right\}\left\{\mathrm{CrL}^{\mathrm{N} 302 \mathrm{Ph}}(\mathrm{CN})_{2}\right\}_{2}\right] .2 \mathrm{H}_{2} \mathrm{O}$, 3. (a) detail of the disordered $\mathrm{L}^{\mathrm{N} 5 \mathrm{Ph} n \mathrm{nMe}}$ ligand and best modeling, (b) ORTEP plots of asymmetric unit, (c) crystal packing.
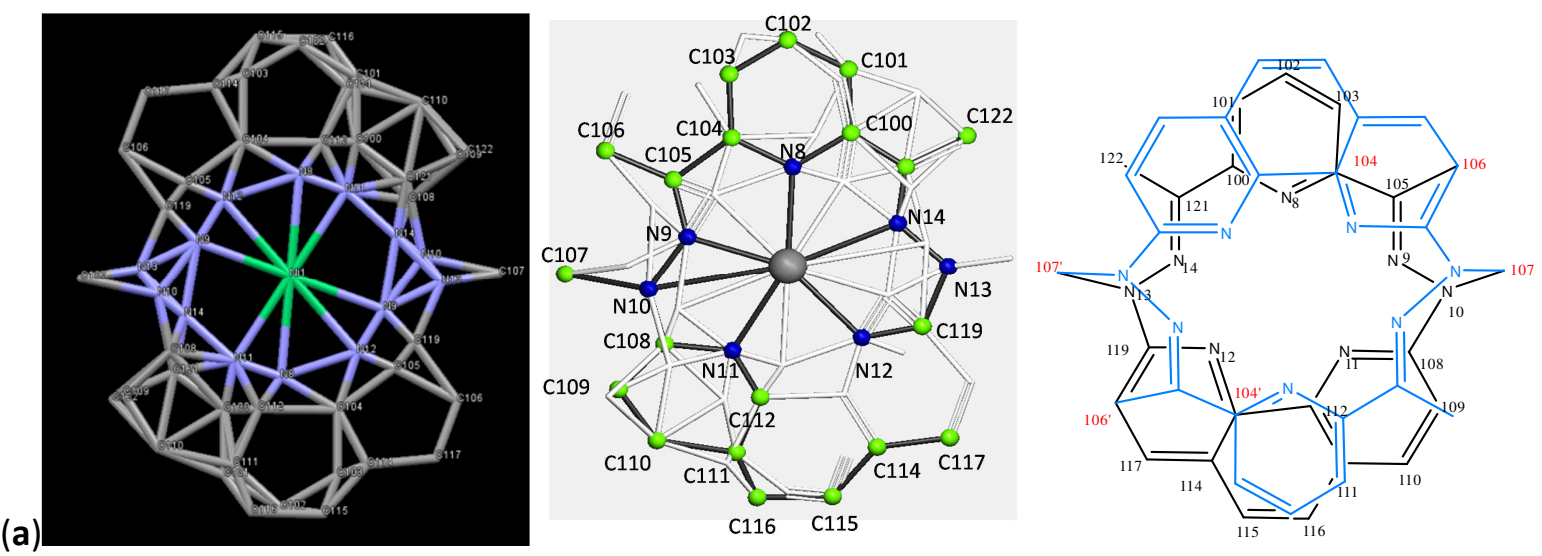

Atoms C104, C106, and C107 (in red in the sketch) have occupancy of 1 while all the other positions have occupancy of 0.5 . Symmetry code: ' $=1-x, 2-y, 1-z$

(b)

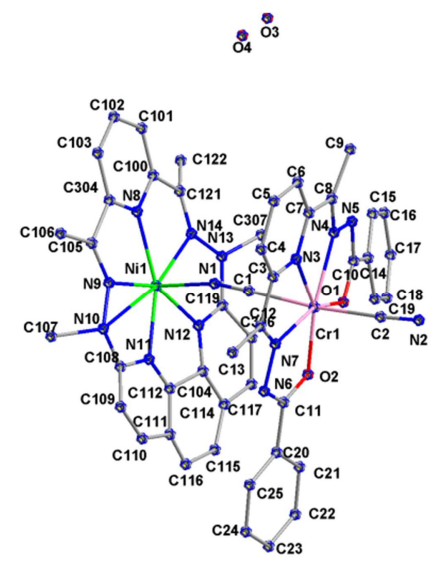

(c)
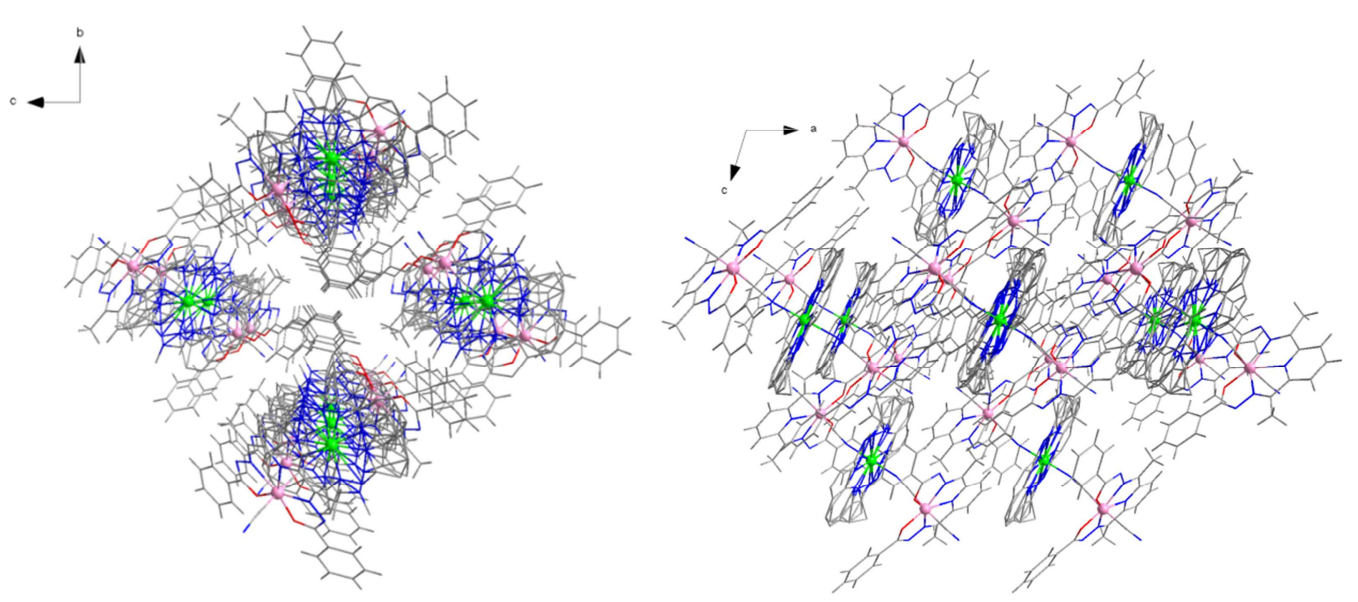

Shortest intermolecular distances between metal enters:

$\operatorname{Cr} 1-\operatorname{Cr} 1^{2-x, 2-y, 1-z}, 8.284(1) \AA ; \operatorname{Cr} 1-N i 1^{1+x, y, z}, 8.5635(7) \AA$ 
Selected bond distances $(\AA)$ and angles $\left({ }^{\circ}\right)$

$\begin{array}{lll}\text { Ni1 } & \text { N1 } & 2.0753(42) \\ & \text { N8 } & 2.1661(62) \\ \text { N9 } & 2.1194(114) \\ \text { N11 } & 2.1673(86) \\ \text { N12 } & 2.1661(84) \\ \text { N14 } & 2.406(8)\end{array}$

Ni1-N1-C1, 165.50(38)

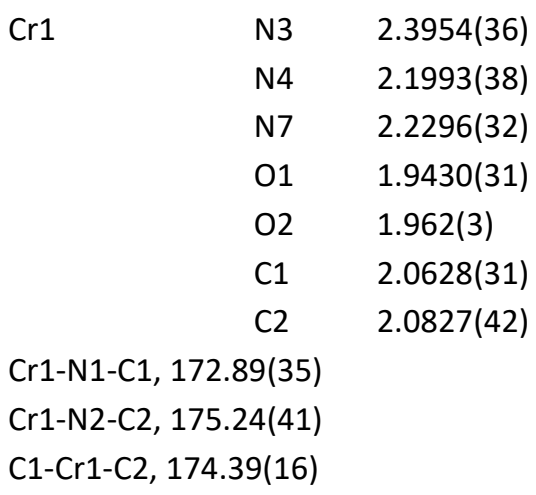

Figure S5 Powder X-Ray patterns for $\left[\left\{\mathrm{NiL}^{\mathrm{NSPhenMe}}\right\}\left\{\mathrm{CrL}^{\mathrm{N} 302 \mathrm{Ph}}(\mathrm{CN})_{2}\right\}_{2}\right] \cdot 2 \mathrm{H}_{2} \mathrm{O}, \mathbf{3}$ : (up) experimental diffractogram (blue line) obtained from the crystals batch and (down) calculated diffractogram (red line) deduced from the single crystal X-Ray diffraction.

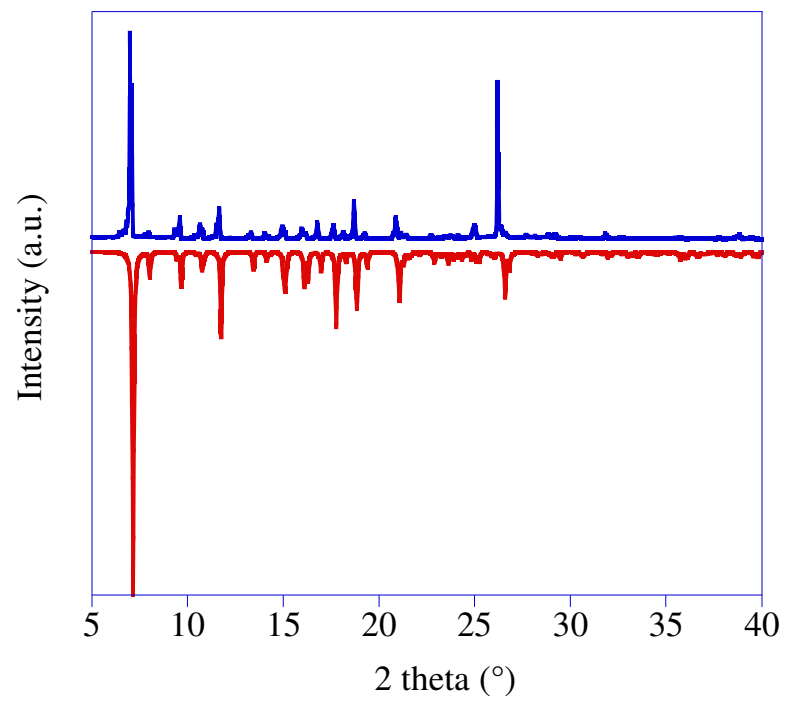


Figure S6 [\{NiL $\left.\left.{ }^{\text {N5PhenMe }}\right\}\left\{\mathrm{CrL}^{\mathrm{N3O2Ph}}(\mathrm{CN})_{2}\right\}\right] . \mathrm{dmf} . \mathrm{ClO}_{4}, 4$ : (a) ORTEP plot of asymmetric unit (ellipsoids are drawn at the $30 \%$ probability level), (b) Crystal packing, (c) inter-chain arrangement and relative organization of the Ni moieties, the colored surfaces materialize the plane crossing the atoms N8, N11 and N12 of the $\left[\mathrm{NiL}^{\mathrm{N}}{ }^{\mathrm{PPh}} \mathrm{Me}\right]$ moieties.

(a)
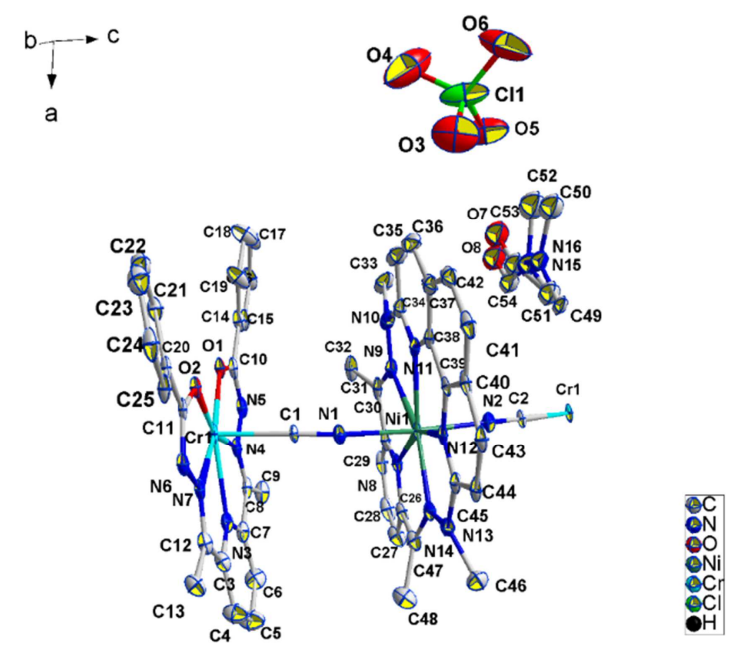

(b)
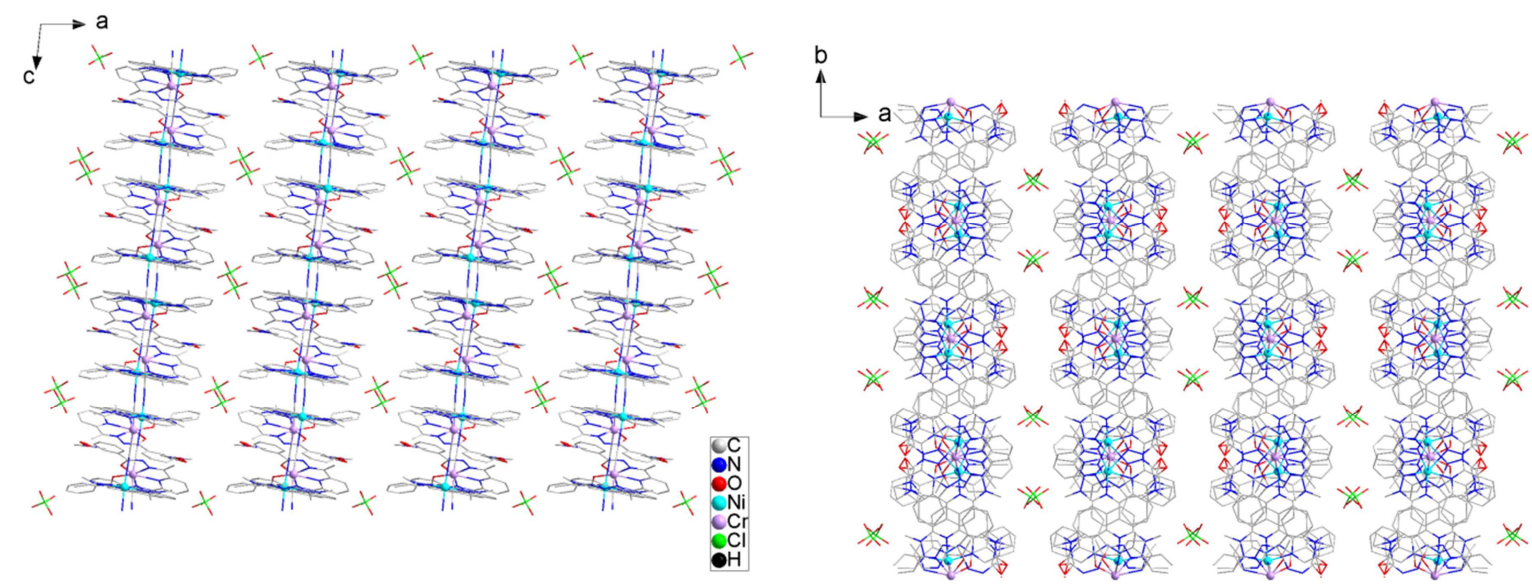

(c)
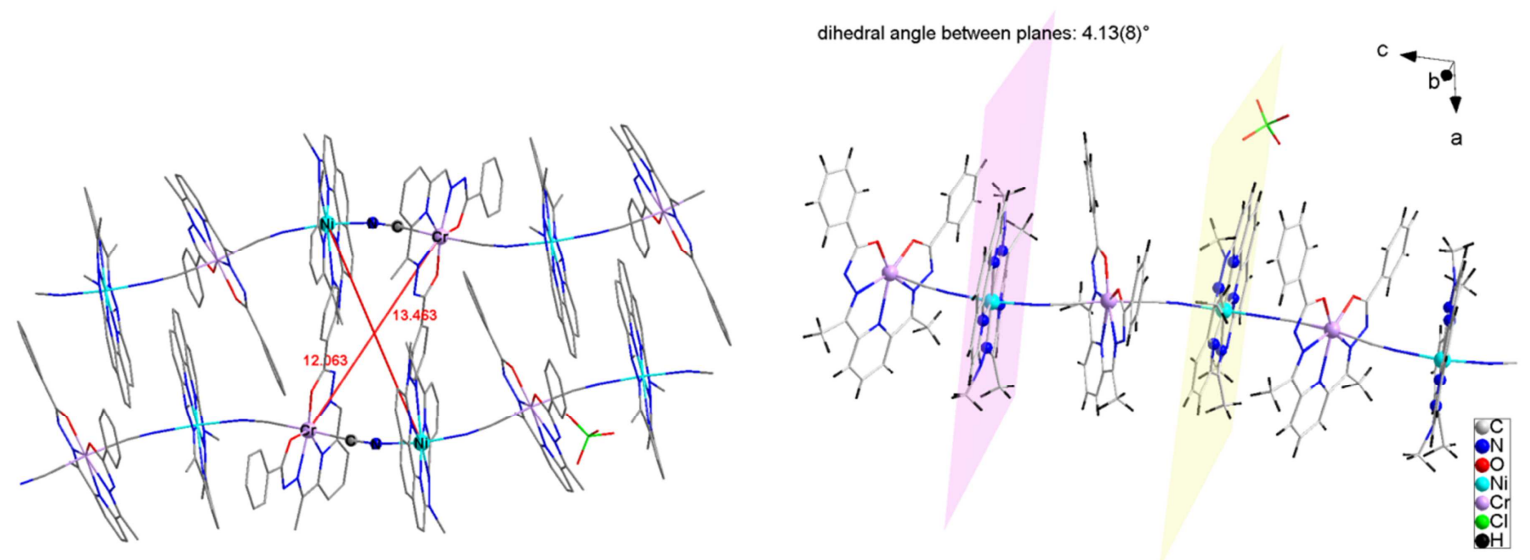
Selected bond distances $(\AA \AA)$ and angles $\left({ }^{\circ}\right)$

$\begin{array}{lll}\text { Ni1 } & \text { N1 } & 2.0639(29) \\ & \text { N2 } & 2.0704(29) \\ & \text { N8 } & 2.1365(32) \\ & \text { N9 } & 2.5553(34) \\ \text { N11 } & 2.2053(33) \\ & \text { N12 } & 2.0094(27) \\ & \text { N14 } & 2.1054(34)\end{array}$

N1-Ni1-N2, 170.16(11)

Ni1-N1-C1, 170.71(26)

Ni1-N2-C2, 167.47(27)
Cr1

$\begin{array}{ll}\text { N3 } & 2.3900(33) \\ \text { N4 } & 2.2313(29) \\ \text { N7 } & 2.2077(32) \\ \text { O1 } & 1.9524(28) \\ \text { O2 } & 1.9594(24) \\ \text { C1 } & 2.0554(30) \\ \text { C2 } & 2.0641(31)\end{array}$

Cr1-N1-C1, 172.31(27)

Cr1-N2-C2, 171.65(27)

C1-Cr1-C2, 163.86(12)

Figure S7 Powder X-Ray patterns for $\left[\left\{\mathrm{NiL}^{\mathrm{NSPhenMe}}\right\}\left\{\mathrm{CrL}^{\mathrm{N} 302 \mathrm{Ph}}(\mathrm{CN})_{2}\right\}\right] . \mathrm{dmf} \cdot \mathrm{ClO}_{4}, 4$ : (up) experimental diffractogram (blue line) obtained from the crystals batch and (down) calculated diffractogram (red line) deduced from the single crystal X-Ray diffraction.

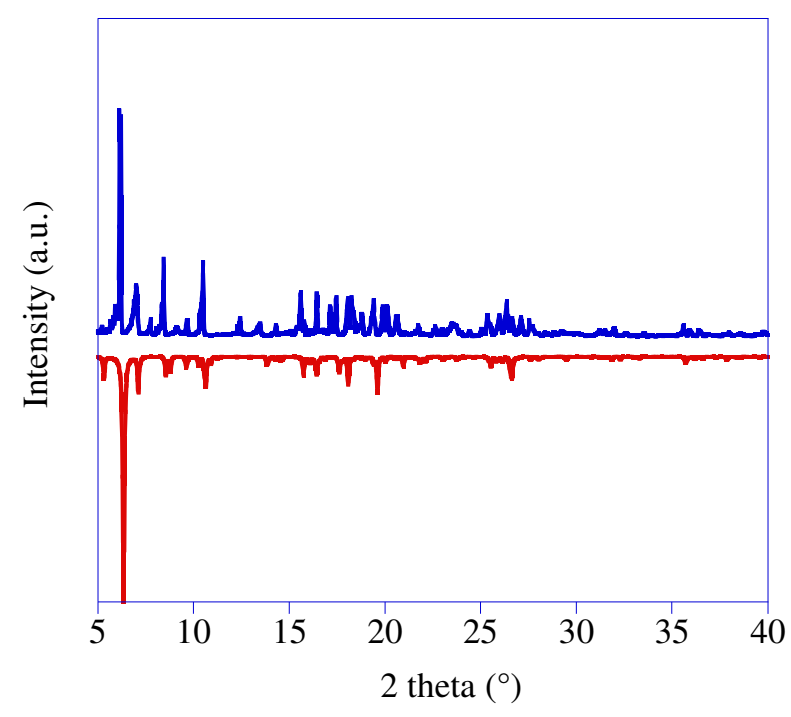


Figure S8 Magnetic behavior for $\left[\mathrm{NiL}^{\mathrm{NSPhenMe}}\left(\mathrm{H}_{2} \mathrm{O}\right)_{2}\right] \cdot 2 \mathrm{BF}_{4}$, 1. Experimental $(\mathrm{O})$ and calculated $(-)$ temperature dependence of $\chi_{M} T$, and isothermal magnetizations.

Best fit ${ }^{4}$ parameters: $D=-10.95 \pm 0.04 \mathrm{~cm}^{-1}, E=1.515 \pm 0.008 \mathrm{~cm}^{-1}, g=2.11$.
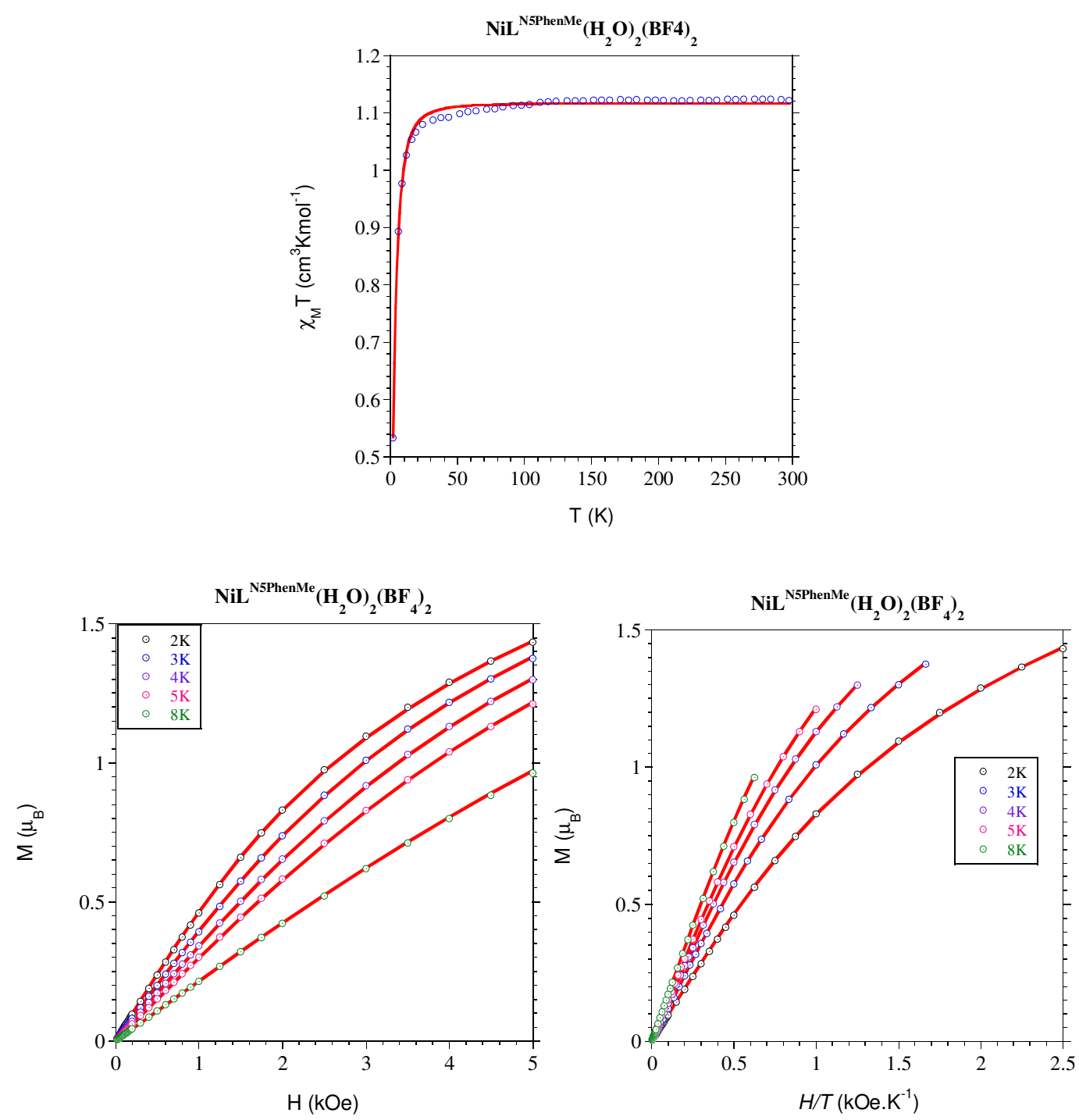

\footnotetext{
${ }^{4}$ Performed with PHI: N. F. Chilton, R. P. Anderson, L. D. Turner, A. Soncini and K. S. Murray, PHI: A powerful new program for the analysis of anisotropic monomeric and exchange-coupled polynuclear $\mathrm{d}$ - and $\mathrm{f}$-block complexes, J. Comput. Chem., 2013, 34, 1164-1175.
} 
Figure S9 Additional magnetic data for $\left[\left\{\mathrm{NiL}^{\mathrm{N} 5 \mathrm{PhenMe}}\right\}\left\{\mathrm{CrL}^{\mathrm{N} 3 \mathrm{O} 2 \mathrm{Ph}}(\mathrm{CN})_{2}\right\}\right] \cdot \mathrm{dmf} . \mathrm{ClO}_{4}, 4$.

1. Temperature dependence of the molar magnetic susceptibility $\left(\chi_{\mathrm{M}}\right)$ with $H_{\mathrm{dc}}=1 \mathrm{kOe}$ (red) and $H_{\mathrm{dc}}=50$ Oe (blue).

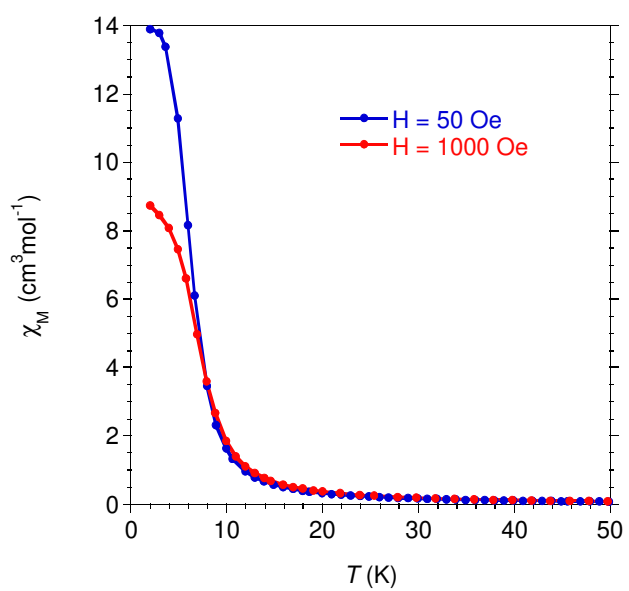

2. Temperature dependence of $\chi_{M}{ }^{\prime}$ and $\chi_{M}{ }^{\prime \prime}$ for $A C$ frequencies between 1 and $1500 \mathrm{~Hz}$ with $H_{\mathrm{ac}}$ $=3$ Oe.
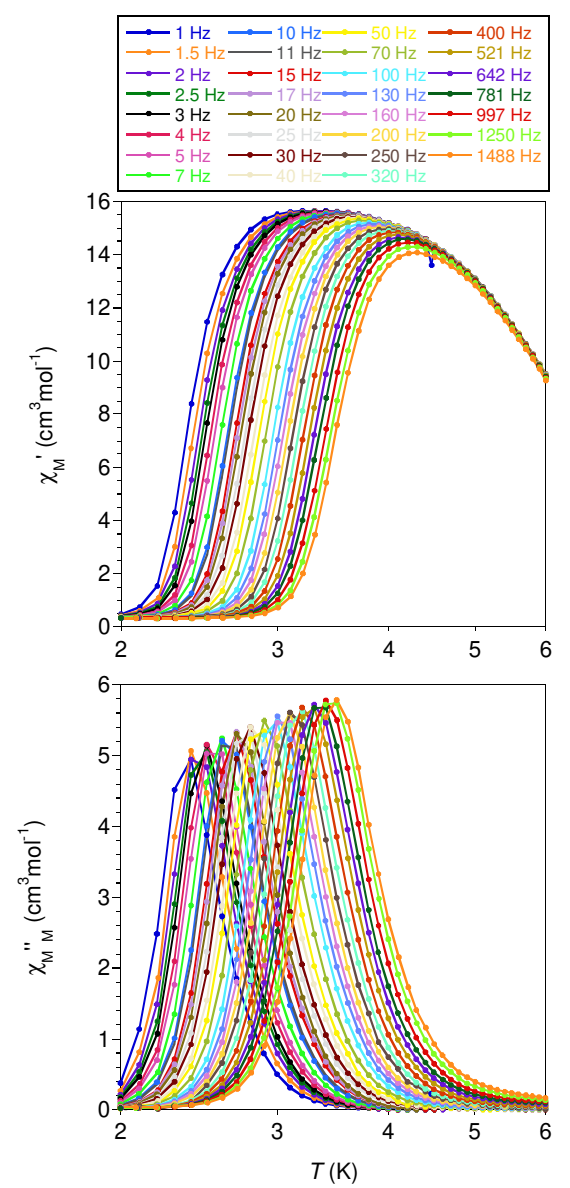
3. Cole-Cole plots and best-fit parameters

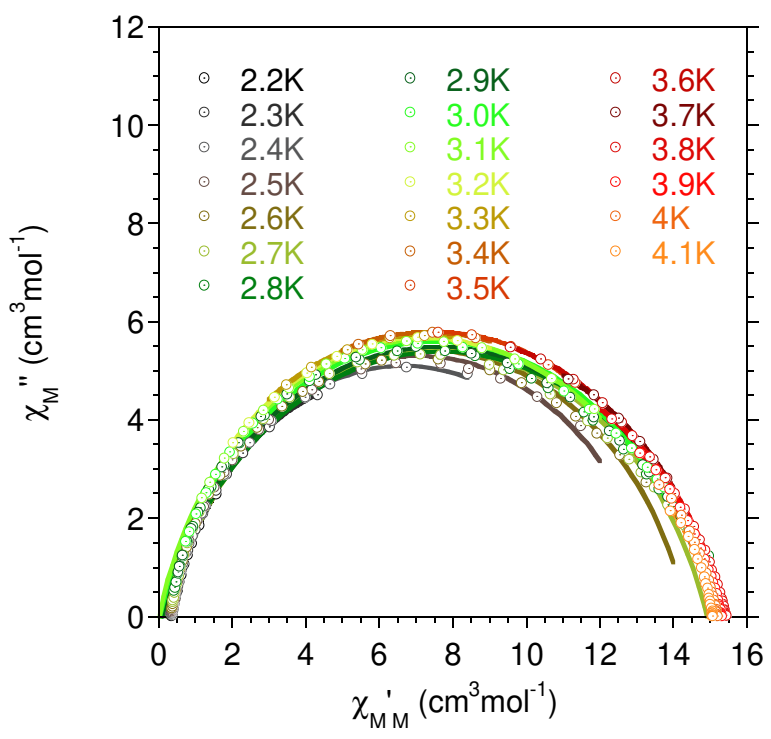

\begin{tabular}{|l|l|l|l|}
\hline \multicolumn{1}{|c}{$\mathrm{T}^{(K)}$} & \multicolumn{2}{c}{$\chi_{\mathrm{T}}$} & \multicolumn{1}{c|}{$\alpha$} \\
\hline $\mathbf{2 . 2}$ & 14.607 & 0.343 & 0.161 \\
\hline $\mathbf{2 . 3}$ & 12.494 & 0.341 & 0.137 \\
\hline $\mathbf{2 . 4}$ & 12.990 & 0.334 & 0.136 \\
\hline $\mathbf{2 . 5}$ & 13.174 & 0.317 & 0.147 \\
\hline $\mathbf{2 . 6}$ & 14.391 & 0.280 & 0.167 \\
\hline $\mathbf{2 . 7}$ & 14.920 & 0.206 & 0.192 \\
\hline $\mathbf{2 . 8}$ & 15.291 & 0.089 & 0.215 \\
\hline $\mathbf{2 . 9}$ & 15.033 & 0.081 & 0.191 \\
\hline $\mathbf{3 . 0}$ & 14.985 & 0.019 & 0.183 \\
\hline $\mathbf{3 . 1}$ & 14.670 & 0.010 & 0.164 \\
\hline $\mathbf{3 . 2}$ & 14.333 & 0.048 & 0.145 \\
\hline $\mathbf{3 . 3}$ & 14.264 & 0.058 & 0.136 \\
\hline $\mathbf{3 . 4}$ & 14.621 & 0.017 & 0.147 \\
\hline $\mathbf{3 . 5}$ & 14.892 & 0.114 & 0.153 \\
\hline $\mathbf{3 . 6}$ & 15.044 & 0.570 & 0.151 \\
\hline $\mathbf{3 . 7}$ & 15.410 & 0.031 & 0.197 \\
\hline $\mathbf{3 . 8}$ & 15.434 & 1.248 & 0.195 \\
\hline $\mathbf{3 . 9}$ & 15.313 & 2.935 & 0.172 \\
\hline $\mathbf{4 . 0}$ & 15.189 & 5.099 & 0.139 \\
\hline $\mathbf{4 . 1}$ & 15.07 & 6.661 & 0.119 \\
\hline $\mathbf{4 . 2}$ & 14.92 & 6.873 & 0.126 \\
\hline
\end{tabular}

